XXV.

\title{
Häufigkeit und Ursachen seelischer Erkrankungen in der deutschen Marine unter Vergleich mit der Statistik der Armee.
}

Von

\author{
Harine-Stabsarzt Dr. Podestà \\ in Berlin.
}

(Nit 7 Zinkographien.)

In den letzten Jahrzehnten ist wiederholt die Aufmerksamkeit auf das verhältnissmässig häufige und zunehmende Auftreten von seelischen Erkrankungen in der Armee gelenkt worden. Von dem Standpunkt ausgehend, dass in einem Heere, dessen Truppen sich durchweg aus ausgewählten jugendlichen und gesunden Mannschaften rekrutiren, eigentlich seelische Störungen unter den Soldaten zu den seltenen Ausnahmen. gehören sollten, hat man die Einwirkungen des militärischen Lebens und seiner besonderen Eigenthümlichkeiten einem kritischen Studium unterworfen, um die Gründe für das häufige Vorkommen von Psychosen beim Militär kennen zu lernen und die Möglichkeit ihrer Bekämpfung und Einschränkung in's Auge zu fassen.

Die langsame, aber gleichmässig fortschreitende Zunahme der Geisteskrankheiten in der Armee geht deutlich aus der dem Sanitätsbericht über die Preussische Armee für den Berichtszeitraum 1900/1901 entnommenen statistischen Uebersicht über die Häufigkeit dieser Erkrankungen hervor (siehe Tafel I). Darnach hat sich, nachdem im Jahre 1874/75 die durch die Feldzüge hervorgerufene Steigerung überwunden und die Zahl der Erkrankten auf 0,21 p.M. der Kopfstärke gefallen war, diese Zahl durch allmälige Zunahme jetzt auf das Dreifache erhöht $(0,63$ pM.).

So gewaltig diese Zunahme auf den ersten Blick erscheinen mag, so gewinnt sie doch ein weniger beängstigendes Ansehen, wenn man ihr das mindestens ebenso schnelle und hohe Anwachsen der geistigen Archiv für Psychiatrie. Bd. 40. Høft 3. 
Erkrankungen in der gesammten Bevölkerung gegenüberstellt, die grade in den letzten Jahrzebnten sich in so erschreckender Weise bemerkbar gemacht hat. Denn welches auch immer die Gründe dieser allgemeinen Zunahme der seelischen Erkrankungen seien, es steht fest, dass diejenigeu Einwirkungen, welche das Anwachsen bei der Civilbevölkerung begründen, auch bei der anschwellenden Zahl der Geisteskrankheiten in der Armee ihre Hand im Spiele haben, auch trotz der durch die genauere Kenntniss dieser Erkrankungen bedingten vorsichtigeren Auswahl des Soldatenmaterials.

Ziffermässig erscheint allerdings der Antheil der reinen Geisteskrankheiten im Vergleich zu der Gesamtheit aller anderen im Heere vorkommenden Krankheiten ein recht geringer, wenigstens wie sie in den Sanitätsberichten in der Nummer 41: "Geisteskrankheiten" des Rapportmusters unter der Gruppe II: "Krankheiten des Nervensystems" erscheinen. Doch darf nicht ausser acht gelassen werden, dass eine Reihe von seelischen Störungen unter anderen Rubriken zu suchen ist, z. B. unter Epilepsie, Neurasthenie und Hysterie. Besonders unter der Diagnose Neurasthenie verbirgt sich eine nicht unbeträchtliche Anzahl von beginnenden Störungen des Seelenlebens, die sich im weiteren Verlauf als Anfangsstadien reiner Geisteskrankheiten ausweisen. Ausserdem müssen die als Complication und Folgezustände acuter und chronischer Infectionszustände, die nach Unfällen, Vergiftungen u. s. w. auftretenden geistigen Erkrankungen und nicht zuletzt die Selbstmorde und Selbstmordversuche zur Beurtheilung ihrer Häufigkeit herangezogen werden.

Mehr noch als die absolute Frequenz muss die stete Zunahme der seelischen Erkrankungen bedeutungsvoll und bedenklich erscheinen, wenn man erwägt, dass es sich bei der weitaus grössten Mehrzahl aller dieser Fälle nicht wie sonst um mehr oder weniger schnell vorübergehende und mit Heilung endigende Krankheiten handelt, sondern wenigstens bei den reinen Geisteskrankheiten fast ausnahmslos um Leiden, welche von der grössten Bedeutung für das ganze Leben des Kranken sind und stets die weitere Militärbrauchbarkeit in Frage stellen.

Nicht mit Unrecht hat man von jeher neben dem Alter und Geschlecht der Einwirkung der. Thätigkeit und Beschäftigung auf die Entstehung und Ausbildung von Seelenstörungen eine grosse Bedeutung beigelegt, und es ist wohl bekannt, dass gewisse Berufsstände zur Auslösung und Entstehung seelischer Erkrankungen mehr disponiren als andere. Einen Einfluss in diesem Sinne übt zweifellos auch der Militärstand aus, indem er theils gewisse Krankheitsformen häufiger zur Beobachtung gelangen lässt als sonst, theils diesen manche charakteristische 
Färbung verleiht. Diese Erkenntniss, dass die Vorstellungen und Handlungen geisteskranker Soldaten durch persönliche Eindrücke und Beziehungen einen specifischen Beigeschmack erhalten, hat dazu geführt, solche Krankheiten allgemein mit dem Namen "Militärpsychosen" zu bezeichnen.

Es liegt auf der Hand, dass bezüglich des Vorkommens dieser Seelenstörungen die angeführten Verhältrisse eine sinngemässe Anwendung auf den der Armee am nächsten stehenden Stand, nämlich auf die Marine, finden müssen, und es erscheint daher von Interesse, die hauptsächlich zur Beobachtung kommenden seelischen Erkrankungen bei der Marine bezüglich ibrer Häufigkeit in Parallele zu denen in der Armee zu stellen und an der Hand der gefundenen statistischen Resultate auf die Beantwortung der Frage einzugehen, ob dem Marinedienst gewisse Eigenthümlichkeiten inne wohnen, welchen ein besonderer Einfluss auf die Entstehung solcher Erkrankungen zuzuschreiben ist.

Man wird also bei der Beurtheilung der Häufigkeit seelischer Erkrankungen in der Marine in erster Linie die auch für die Landarmee in Betracht kommenden Verhältnisse berücksichtigen müssen, denn eine ganze Reihe von Gesichtspunkten, die für die Begründung des hüufigen Vorkommens und vor Allem der Zunahme seelischer Erkrankungen bei der Armee in Frage kommen, wird natürlich in ähnlicher Weise und in analogem Sinne auch bei der Marine in Rechnung zu ziehen sein. In zweiter Linie müssen aber die speciell in den Eigenthümlichkeiten des Marinedienstes beruhenden Verhältnisse einer besonderen Würdigung unterzogen und daraufhin geprüft werden, ob sie mit den in der Marine am meisten vorkommenden Seelenstörungen in einen ursächlichen $\mathrm{Zu}$ sammenhang zu bringen sind und dieselben in der Häufigkeit ibres Auftretens beeinflussen.

In der Kurventafel I sind den Zahlenwerthen der Geisteskrankheiten in der Armee, berechnet auf 1000 der Iststärke, diejenigen in der Marine gegenübergestellt. Ein Blick auf diese Tafel lässt erkenuen, dass, während die Linie der Geisteskrankheiten der Armee eine durchaus gleichmässige, stetig ansteigende Tendenz zeigt, die Kurve für die llarine bei weitem grössere Schwankungen von Jahr zu Jạhr aufweist. Indessen ist auch bier ein deutliches Anschwellen der Werthe zumal im letzten Jahrzehnt nicht zu verkennen, indem die tiefen Remissionen in der Kurve der achtziger Jahre nicht wieder erschienen sind und auch die Gipfelpunkte höher liegen als vordem. Durchschnittlich erreichen die Ziffern bei der Narine einen etwas höheren Werth als bei der Armee. In dem letzten zwölfjährigen Zeitraum von 1889 bis 1901 z. B. sind die promillarisuhen Zahlen bei der Armee nur $4 \mathrm{mal}$ etwas grösser gewesen, 


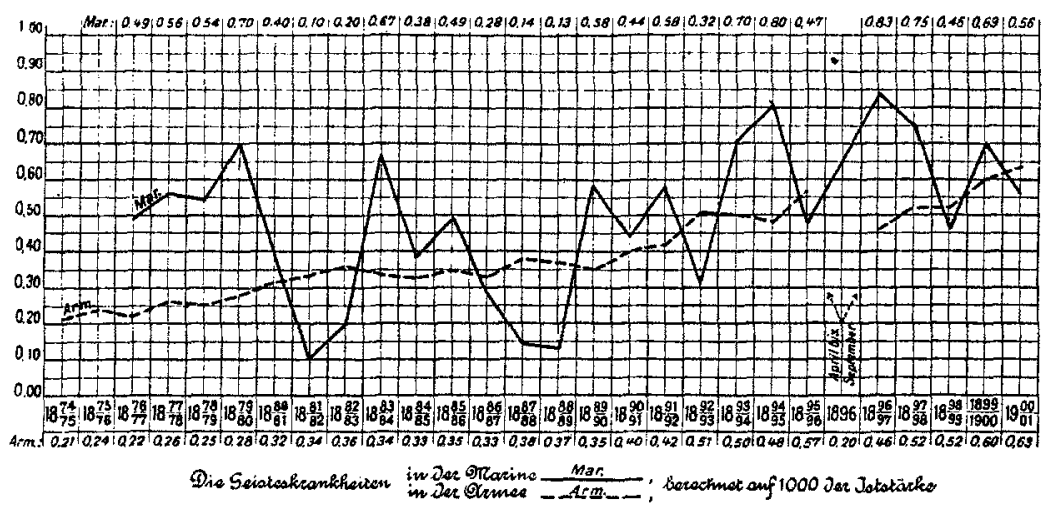

Tafel I.

als bei der Marine, und zwar um 0,07 bis $0,20 \mathrm{pM}$. Bei der Marine dagegen übertrafen die Zahlen diejenigen der Armee $8 \mathrm{mal}$, und zwar um 0,05 bis $0,35 \mathrm{pM}$. Wärend aber die Zahl der Geisteskrankheiten in der Armee seit dem Kriege 1870/71 sich in fortgesetzt steigender Tendenz bewegt und im Berichtjahre 1900/01 mit 0,63 pM. einen Höhepunkt erreicht hat, ist die böchste Zahl bei der Marine mit $0,83 \mathrm{pM}$. bereits im Jahre 1896/97 erreicht worden und seitdem bewegt sich die Hüufigkeitskurve in unregelmässig absteigender Richtung. In Folge dessen ist die Frequenziffer der Narine für das letzte Berichtsjahr 1900/01 mit 0,56 pM. sogar etwas niedriger als diejenige der Armee mit $0,63 \mathrm{pM}$. Trotzdem steht die Durchschnittsziffer der Geisteskrankheiten in der Marine in den angezogenen 12 Jabren mit $0,606 \mathrm{pM}$. noch um $0,11 \mathrm{pM}$. höber als diejenige der Armee mit 0,497 p M. Vergleicht man die erste Hälfte dieses zwölfjährigen Zeitraums mit der späteren, so hat sich in der Marine die sechsjährige Durchschnittsziffer der Geisteskrankheiten von 0,57 auf $0,63 \mathrm{pM}$, also um $0,06 \mathrm{pM}$. erhöht, während sie in der Armee von 0,44 auf $0,55 \mathrm{pM}$, also um $0,11 \mathrm{pM}$. gestiegen ist. Diese Differenz in der Zunahme von 0,05 pM. zu Gunsten der Marine beweist also, dass das Anwachsen der Geisteskrankheiten in der Marine in den letzten 12 Jahren durchschnittlich ein etwas geringeres gewesen ist, als in der Armee. Die Verschiebung dieses Verhältnisses zu Gunsten der Marine findet, wie bereits erwähnt, auch darin ihren Ausdruck, dass die zunehmende Tendenz der Geisteskrankheiten, die bei der Armee eine stetig gleichmässige geblieben ist, bei der Marine sich seit dem Berichtjahre 1896/97 in eine abnehmende verwandelt hat. Mit anderen Worten ausgedrückt, es sind sich die jeweiligen ziffermässigen Werthe 
bei Armee und Marine durch geringeres Anwachsen bei der letzteren allmälig einander näher gerückt.

Ein für die Marine etwas ungüristigeres Bild ergiebt sicb indess bei einem Vergleich der durchschnittlichen promillarischen Zahl der Geisteskrankheiten in den letzten 12 Jahren mit derjenigen für die vorhergehende Periode von 12 Jahren. Bei der Armee hat eine Vermehrung von 0,325 pM. für den Durchschnitt der Jahre 1877 bis 1889 auf 0,495 pMl., für den Durchsehnitt der Jahre 1889 bis 1901, also um $0,17 \mathrm{pM}$. stattgefunden, bei der Marine aber haben sich die betreffenden Ziffern von $0,38 \mathrm{pM}$. auf $0,60 \mathrm{pM}$., also um $0,22 \mathrm{pM}$. erhöht. Es hat demnach bei der Marine eine um $0,05 \mathrm{p} M$. grössere Vermehrung der Geisteskrankheiten für den Durchschnitt der letzten. 12jährigen Periode gegenüber demjenigen des vorhergehenden Zeitraumes von 12 Jahren stattgefunden als bei der Armee.

Im Gesammtdurebschnitt endlich dieser beiden 12jährigen Perioden, also der letzten 24 Jahre seit 1877 betrug die promillarische Ziffer der Geisteskrankheiten bei der Harine 0,49 pll. entgegen 0,41 pll. bei der Armee, so dass die erstere für den genannten Zeitraum absolut um $0,08 \mathrm{pM}$. der Iststïrke mehr an Geisteskranken aufweist als die letztere. Mit anderen Worten auf 100 Geisteskrankheiten in der Marine kommen nur 83,7 in der Armee oder die Marine weist für den Durchschnitt dieser 24 Jahre $1 / 5=20$ pCt. mehr Geisteskrankheiten auf als die Armee.

Für beide, Armee wie Marine, ist demnach eine Zunahme der Geisteskrankheiten statistisch nachzuweisen. Bei der Armee ist diese Zunahme eine gleichmässige und stetige gewesen und hält zur Zeit noch an. Die Zahl dieser Krkrankungen hat sich hier in den letzten 20 Jahren genau verdoppelt, in noch nicht ganz 30 Jahren verdreifacht.

Die Marine weist absolut eine um $20 \mathrm{pCt}$. höhere $\mathrm{Zahl}$ von Geisteskrankheiten als die Armee auf und zeigt ebenfalls ein Anwachsen derselben, doch ist dasselbe unregelmässig und inconstant, auch dauert es augenblicklich nicht mehr an, sondern ihre Zahl bewegt sich seit dem Erreichen eines Höhepunktes im Jahre 1896/97 in unregelmässig absteigender Linie.

Das Maass der Zunahme betrug in Armee wie Marine ziemlich das Gleiche. Der bei der Marine von Jahr zu Jahr beträchtlich schwankenden Ziffern halber können nur die Durchschnittswerthe längerer,Perioden zu einem Vergleich mit der Armee benutzt werden. Für den Durchschnitt der letzten 12jährigen Periode verglichen mit der vorhergehenden gleichen Periode stellt sich die Zunahme für die Armee anf $52 \mathrm{pCt}$, 
für die Marine auf $54 \mathrm{pCt}$., also auf etwas mehr als die Hälfte für beide Wehrgattungen.

In den folgenden Tabellen sind die im Texte oben angeführten Durchschnittsziffern in übersichtlicherer Weise zusammengestellt.

\begin{tabular}{|c|c|c|c|c|c|}
\hline & $\begin{array}{l}1877 / 78 \\
\text { bis } \\
1882 / 83 \\
\text { pM. }\end{array}$ & $\begin{array}{l}1883 / 84 \\
\text { bis } \\
1888 / 89 \\
\text { pM. }\end{array}$ & $\begin{array}{c}1889 / 90 \\
\text { bis } \\
1894 / 95 \\
\text { pN. }\end{array}$ & $\begin{array}{c}1895 / 96 \\
\mathrm{bis} \\
1900 / 01 \\
\mathrm{pM} .\end{array}$ & $\begin{array}{l}1877 / 78 \\
\text { bis } \\
1900 / 01 \\
\text { pM. }\end{array}$ \\
\hline $\begin{array}{l}\text { Marine } \\
\text { Armee } \\
\text { mithin mehr in d. Marine }\end{array}$ & $\begin{array}{l}0,41 \\
0,30 \\
0,11\end{array}$ & $\begin{array}{l}0,35 \\
0,35 \\
-\end{array}$ & $\begin{array}{l}0,57 \\
0,44 \\
0,13\end{array}$ & $\begin{array}{l}0,63 \\
0,55 \\
0,08\end{array}$ & $\begin{array}{l}0,49 \\
0,41 \\
0,08\end{array}$ \\
\hline
\end{tabular}

Diese Tabelle giebt die durchschnittliche Zahl der Geisteskrankheiten in Marine und Armee, berechnet auf je 1000 der Iststïre, in 4 Zeiträumen von 6 za 6 aufeinanderfolgenden Jahren, sowie die Durchschnittszahl für die ganze 24 jährige Periode wieder.

In der folgenden Tabelle sind dieselben promillarischen Werthe, aber auf zwei 12 jahhrige Zeiträume reducirt aufgestellt und mit einanter verglichen.

\begin{tabular}{l|c|c|c}
\hline & $\begin{array}{c}1877 / 78 \\
\text { bis } \\
1888 / 89 \\
\mathrm{pM}\end{array}$ & $\begin{array}{c}1889 / 90 \\
\text { bis } \\
1900 / 01 \\
\mathrm{pM}\end{array}$ & Zunahne \\
& $\mathrm{pM}$. \\
\hline Marine . . . . . & 0,38 & 0,60 & 0,22 \\
Armee .. . . . & 0,33 & 0,50 & 0,17 \\
Unterschied . . . . & 0,05 & 0,10 & 0,05
\end{tabular}

Es ist bereits darnuf hingewiesen, dass rein ziffermässig betrachtet der Antheil der Geisteskrankheiten im Vergleich zur Gesammtheit aller anderen Erkrankungen in der Armee ein recht geringer ist. Unsere für die Marine anfgestellte Statistik lüsst für diese dieselbe Annahme gültig erscheinen, da der geringe Unterschied in der Frequenz der Geisteskrankheiten zu Ungunsten der Marine nicht ins Gewicht fallen kann. Bedenklicher sieht schon das durch die Statistik für beide, Marine wie Armee nachzuweisende Anwachsen dieser Erkrankungen in den letzten Jahrzehnten aus. In noch ungünstigerem Lichte wird aber diese $\mathrm{Zu}$ nahme erscheinen, wenn wir die steigenden Häufigkeitsziffern der Geisteskrankheiten in Vergleich setzen zu den jährlichen Zahlen des Gesammtkrankenstandes pMl. der durchsehnittlichen Kopfstärke (Iststärke). Sowohl in der Marine wie in der Armee hat seit dem Kriege 1870/71 
die Höhe des Krankenstandes ziemlich gleichmässig und beständig abgenommen. Bei beiden wurden im letzten Berichtsjahre 1900/01 die niedrigsten Werthe erreicht, die bei der Armee mit 649,3 pM. weniger als die Hälfte der Durchschnittsziffer für das Jahr 1873/74 mit 1311,8 pM. und bei der Marine mit $690,6 \mathrm{pM}$. sogar weniger als die Hälfte des Krankenstandes für $1879 / 80$ mit $1560,7 \mathrm{pM}$. betrugen. An dieser erfreulichen Abnahme des Krankenstandes betheiligen sich:also die Geisteskrankheiten nicht nur nicht, sondern ihr Antheil ist sogar trotz der Abnahme des Krankenstandes im Allgemeinen ein deutlich wachsender geworden. Selbst wenn er absolut derselbe geblieben wäre, würde dies angesichts des Rückganges der allgemeinen Krankeuziffern eine relative Zunahme der Geisteskrankheiten bedeuten.

Wie schon erwähnt, kann die Betrachtung der Geisteskrankheiten allein nicht genügenden Aufschluss über die Häufigkeit seelischer Erkrankungen bei der Mlarine und der Armee geben, sondern es müssen zu diesem Zwecke auch diejenigen Krankheitsgruppen Berücksichtigung finden, unter denen sich erfahrungsgemäss ein nicht geringer Theil seelischer Störungen, zumal in ihrem Begiun verbirgt. In erster Linie handelt es sich hier ausser der Epilepsie um die Neurasthenie und die Hysterie, welch letztere erst seit dem Berichtsjahre 1896/97 bezw. $1897 / 98$ in den Sanitätsberichten von Armee und Marine als selbstständige Krankheitsnummern aufgefübrt sind. Vorher hatten dieselben im Rapportmuster unter der Gruppe: „Andere Krankheiten des Nerven-

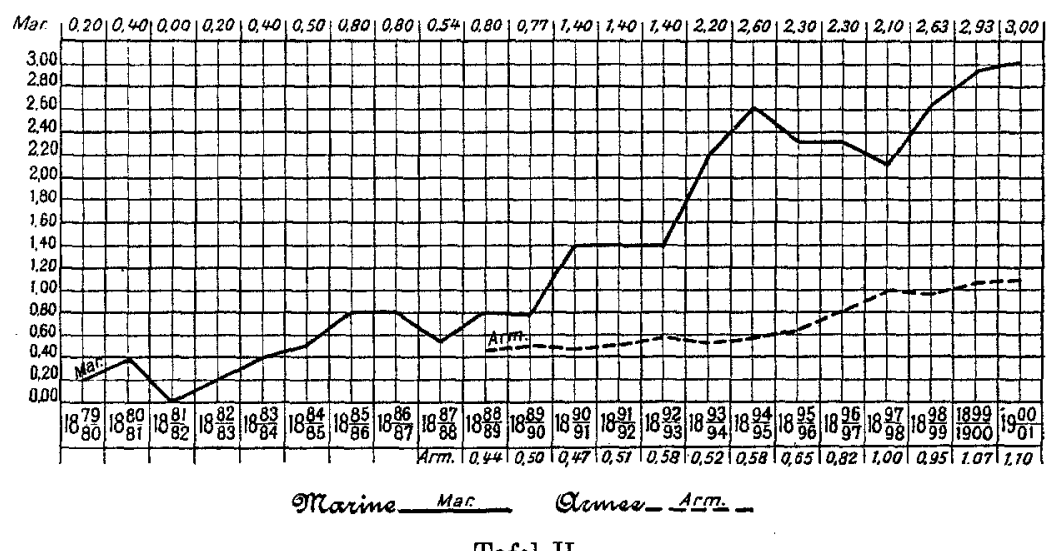

Tafel II.

systems" Aufnahme gefunden, deren hauptsächlichsten Bestandtheil sie bildeten. Die Kurventafel II gieht eine Aufstellung der Krankheitsfrequenz dieser Gruppe, welche einen Vergleich zwischen Marine und 
Armee zulässt. Für beide ergiebt sich ohne Weiteres eine ziemlich starke Zunahme dieser Erkrankungen. Ebenso wie bei den Geisteskrankheiten ist die Zunahme bei der Marine stärker und ungleichmässiger als bei der Armee. Auf den Durchschnitt der drei letzten 6 jährigen Perioden seit $1883 / 84$ berechnet hat sich in der Marine die Zahl der Frkrankungen dieser Gruppe einschliesslich der in den letzten Sanitätsberichten gesondert anfgeführten Neurasthenie und Hysterie vervierfacht. Es litten nämlich an diesen Erkrankungen, auf 1000 der Iststärke berechnet, durchschnittlich in der sechsjährigen Periode von

$$
\begin{aligned}
& 1883 / 84 \text { bis } 1888 / 89 \text {. . . } 0,64 \mathrm{pM} \text {. } \\
& 1889 / 90 \text { bis } 1894 / 95 \text {. . } 1,63 \mathrm{pH} \text {. } \\
& 1895 / 96 \text { bis } 1900 / 01 \text {. . 2,54 pM. }
\end{aligned}
$$

An diesem rapiden Anschwellen trägt in erster Linie die Zunahme der neurasthenischen Erkrankungen Schuld, sie machen allein, dabei in steigender Tendenz, $1 / 3$ bis $1 / 2$ aller Erkrankungen dieser Gruppe aus. Auch die Hysterie betheiligt sich in wachsendem Maassstabe und zwar mit $1 / 3$ bis $1 / 4$.

Auffallend gross sind die Unterschiede, welche die Häufigkeit der Neurasthenie und Hysterie bei der Armee und Marine bieten. Ge naueren Aufschluss darüber giebt dic folgende tabellarische Zusammenstellung, in welcher die promillarischen Werthe der angeführten Erkrankungen aus den 4 letzten. Berichtsjahren für Marine und Armee

\begin{tabular}{|c|c|c|c|c|c|c|c|c|}
\hline \multirow{2}{*}{$\begin{array}{l}\operatorname{lm} \\
\text { Berichts- } \\
\text { jahr }\end{array}$} & \multicolumn{2}{|c|}{ Neurasthenie } & \multicolumn{2}{|c|}{ Hysterie } & \multicolumn{2}{|c|}{$\begin{array}{l}\text { Anderen Krankheiten } \\
\text { des Nerrensystems }\end{array}$} & \multicolumn{2}{|c|}{ Insgesammt } \\
\hline & $\begin{array}{c}\text { Marine } \\
\text { pM. }\end{array}$ & $\begin{array}{c}\text { Armee } \\
\text { pM. }\end{array}$ & $\begin{array}{c}\text { Marine } \\
\mathrm{pM} .\end{array}$ & $\begin{array}{c}\text { Armee } \\
\text { pN. }\end{array}$ & $\begin{array}{c}\text { Marine } \\
\text { pM. }\end{array}$ & $\begin{array}{l}\text { Armee } \\
\mathrm{pM} \text {. }\end{array}$ & $\begin{array}{c}\text { Marine } \\
\text { pM. }\end{array}$ & $\begin{array}{c}\text { Armee } \\
\text { pM. }\end{array}$ \\
\hline & & 0,39 & & 0,29 & & 0,32 & $2,(1-x)$ & 1.0 \\
\hline 1898 & & 0, & & 0, & 0 & 0 & 2,63 & 0,96 \\
\hline $1899 /$ & 0 & 0,4 & 0,8 & 0 & 1, & 0 & 2,93 & 1,07 \\
\hline 190 & 1,37 & 0,4 & 0,8 & 0,3 & 0,8 & 0 & 3,00 & 1,10 \\
\hline $1897 / 1901$ & 1,05 & 0,42 & 0,78 & 0,31 & 0,83 & 0,31 & 2,66 & 1,03 \\
\hline
\end{tabular}
gegenübergestellt sind.

Es erkrankten, auf 1000 der Iststärke berechnet, an:

Es ergiebt sich aus dieser Tabelle, dass Neurasthenie und Hysterie bei der Marine mehr als doppelt, beinahe dreimal so häufig zur Beobachtung kommen, als bei der Armee. Auch ihre Zumahme ist in der Varine eine bedeutend schnellere und starkere, zumal bei der Neurasthenie, denn während die Durchschnittszahl der letzteren Erkrankung in der Armee in -den letzten 4 Berichtsjahren nur um 0,08 pM. zu- 
genommen hat, weist die Marine in demselben Zeitraum eine Zunahme von 0,45 pli. auf.

Es würde aus dem Rahmen unserer Betrachtung fallen, den verschiedenartigen Gründen nachzuforschen, welche das so auffallend häufigere Vorkommen und schnellere Auwachsen der neurasthenischen und in geringerem Maasse auch der. hysterischen Erkrankungen in der Marine herbeigeführt baben. Für unseren $Z$ weck genügt es festzuhalten, dass unter der grösseren Zahl von Erkrankungen dieser Art sich auch entsprechend mehr vorübergehende oder beginnende Seelenstörungen verbergen müssen.

Die Epilepsie, die fast noch öfter als die eben abgehandelten Krankheiten mit psychischen Störungen einhergeht, oder solche im Gefolge hat, ist für die Beurtheilung der Hüufigkeit seelischer Erkrankungen in der Marine von geringer Bedeutung. Ein Vergleich ihres Vorkommens in Armee and Marine ergiebt, dass die Frequenz der Epilepsie überhaupt nur geringen Schwankungen unterliegt, zumal bei der Armee, wo ihr Antheil in den letzten 10 Jahren fast ganz constant geblieben ist. Bei der Marine war zwar die durchschnittliche Zahl der Epileptiker im Allgemeinen etwas grösser als bei der Armee, doch ist seit mehreren Jahren eine deutliche tind gleichmässige Abnahme zu constatiren gewesen. Dieselbe hatte zur Folge, dass im letzten Berichtsjahre 1900/01 die Epilepsie mit 0,53 pMl. bei der Ilarine einen nicht unbedentend niedrigeren Stand einnimıt als bei der Armee mit 0,79 pH. der Iststärke.

Die statistische Zusammenstellung der in der Marine und Armee zur Beobachtung gelangten Geisteskrunkheiten und verwandter Zustände würde unvollkommen sein, wenn nicht die zur Behandlung gekommenen Fälle von Alkoholvergiftungen bezüglich ihrer Häufigkeit eine kritische Beleuchtung erführen. In den Sanitätsberichten erscheinen natürlich nur die wichtigeren und schweren Fälle von Alkobolvergiftung, die eine besondere Behandlung und Beobachtung erheischten. Und gerade diese sind es, welche in der grössten Mehrzahl mit seelischen Störungen einhergehen, die theils als Folgezustande des Alkoholismus, theils als denselben auslösende Ursachen zu betrachten sind. Ebenso wie bei den Geisteskrankheiten ist auch bei den Alkoholvergiftungen die Marine mit etwas höheren Ziffern betheiligt, aber beide zeigen eine deutliche und besonders im letzten Jahrzehnt ziemlich gleichmässig fallende Tendenz. Gegen Ende der $70 \mathrm{er} \mathrm{Jahre} \mathrm{betrug} \mathrm{die} \mathrm{Zahl} \mathrm{der} \mathrm{an} \mathrm{Alkohol-}$ vergiftung Behandelten 0,4 bis $0,5 \mathrm{pM}$. der Iststärke der Marine. Seither haben sich diese Ziffern gleichmässig vermindert; sie erreichten in den beiden letzten Berichtszeiträumen 1897/99 und 1899/1901 ihre 
Minima mit 0,22 und 0,20 pM. Demnach haben sich in den letzten 20 Jahren die an Erscheinungen des Alkoholismus Behandelten in der Marine um mehr als die Hälfte vermindert. Die analogen Ziffern der Armee waren in den gleichen Zeiträumen durchschnittlich nicht unwesentlich niedriger und liessen ebenfalls speziell in letzten Jahrzehnt eine gleichmässige und deutliche Abnahme erkennen. Auch hier fiel das Minimum mit 0,12 pll. auf die letzten Berichtsjahre. Eigenthümlicher Weise wurde bei beiden die höchste Ziffer ebenfalls in demselben Jahre (1878/79) erreicht, und zwar mit 0,70 pll. bei der Marine und mit $0,41 \mathrm{pM}$. bei der Armee. In allen anderen Jahren rücken die Werthe beider einander bedeutend näher. Ueber den Einfluss des Alkoholismus auf die Häufigkeit und das Vorkommen seelischer Störungen speciell in der Marine ist später noch zu sprechen.

Da überstandene oder noch bestehende Geisteskrankheiten einschliesslich hochgradiger geistiger Beschränktheit zum Dienst im Heere und in der Marine untauglich macht, so wird sich der grösste Theil der durch die Statistik nachgewiesenen Geisteskranken in einer statistischen Zusammenstellung der wegen der angeführten Leiden als dienstunbranchbar und invalide Entlassenen wiederfinden. Diese Zahl der Entlassenen wird aber noch vergrössert durch diejenigen Mannschaften, welche sogleich bei der Einstellung als geisteskrank erkannt wurden und ohne erst in ärztlicher Behandlung gewesen zu sein, sofort wieder zur Entlassung gelangten. An diesen Entlassungen baben übrigens - nicht die reinen Geisteskrankheiten allein, sondern die hochgradige geistige Beschränktheit den grössten Antheil, auch wenn dieselbe nicht mit Störungen der seelischen Sphäre verbunden ist. Immerhin bietet die vergleichende Statistik der wegen Geisteskrankheiten und verwandter Zustände bei Armee und Marine als dienstunbrauchbar und ganzinvalide Entlassenen eine werthvolle Unterlage für die Beurtheilung der Häufigkeit sowie der Zunahme seelischer Erkrankungen. Auch für die Frage nach dem Zusammenhang dieser Erkrankungen mit den specifischen Einflüssen des Militär-bezw. Marinelebens kann diese Statistik werthvolle Aufschlïsse geben. Wenn man nämlich annimmt, dass alle diejenigen, bei denen der Dienst in irgend eine ursächliche oder auslösende Beziehung zur Entstehung der geistigen Erkrankung gebracht werden konnte, als invalide zur Entlassung kamen und diesen diejenigen gegenüberstellt, welche wegen ihrer Geisteskrankheit einfach als dienstunbrauchbar entlassen wurden, weil eine dienstliche Schädigung nicht nachzuweisen war, so kann man bieraus noch am ehesten ein allgemeines Bild über die schädigenden Einflüsse des Dienstes für die Entstehung von seelischen Erkrankungen und ihre relative Häufigkeit ge- 
winnen. Ferner lässt sich an der Hand einer vergleichenden Gegenüberstellung der bei der Marine wegen der angeführten Krankheiten Entlassenen zu den bei der Armee zur Entlassung Gelangten ein wichtiger Schluss auf den dadurch herbeigeführten grösseren oder geringeren Verlust der Mannschaft für die eine oder die andere Welurmacht ziehen. Endlich kann man durch einen Vergleich der Zahlenwerthe der als dienstunbrauchbar Ent]assenen mit denen der Invaliden unter gleichzeitiger Gegenüberstellung der für die Mlarine einerseits und für die Armee andererseits ermittelten Zahlen einen brauchbaren Maassstab für die Beurtheilung der verschiedenen Häufigkeit der Verluste sowohl durch Dienstunbrauchbarkeit als auch durch Invalidität gewinnen. Solche statistische Zusammenstellung haben naturgemäss einen um so grösseren Werth, je umfassender und länger die Zeiträume sind, auf die sich die gleichmässigen Berechnungen erstrecken. Um so werthvoller wird dann der Nachweis eines constanten Unterschiedes oder einer gleichmässigen Veränderung in den gewonnenen statistischen Werthen sein.

Die Kurventafel III stellt die Gesammt-Entlassungsziffern wegen

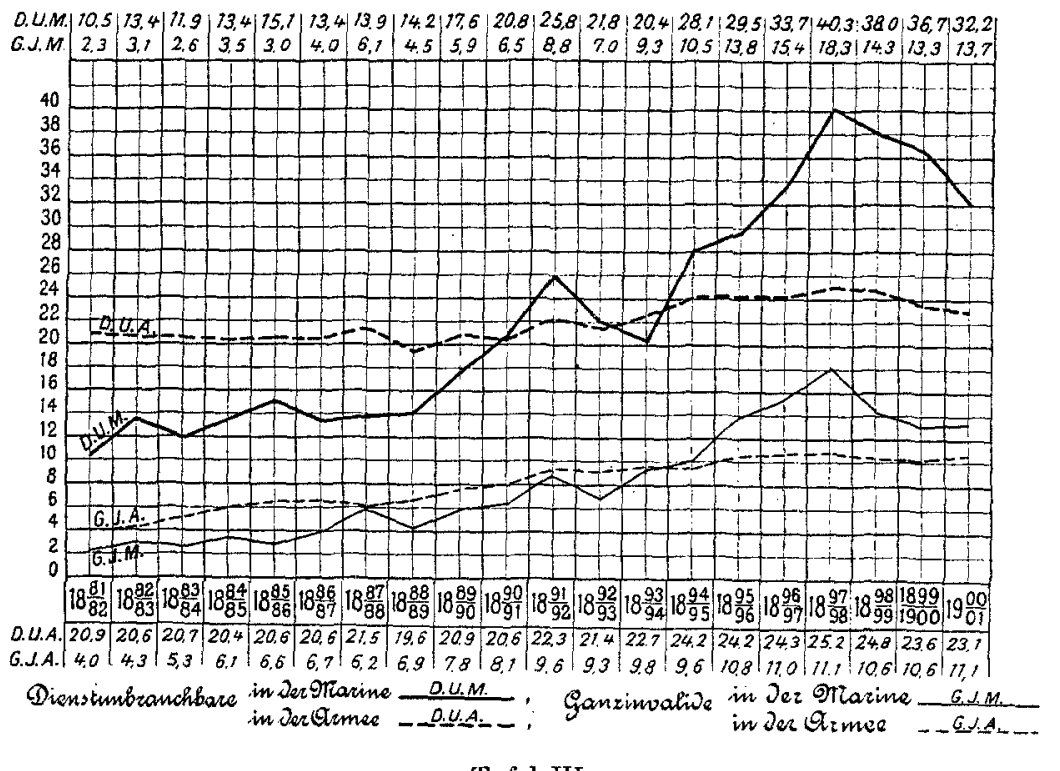

Tafel III.

Dienstunbrauchbarkeit und Ganzinvalidität in Marine und Armee, berechnet auf 1000 der Iststïrke, zusammen. Der Abgang durch Halbinvalidität bleibt unberücksichtigt, weil er durch Geisteskrankheiten 
und verwandte Zustände nicht herbeigeführt wird. Auf den ersten Blick fällt die enorme Zunahme sowohl der wegen Dienstunbrauchbarkeit, als auch der wegen Ganzinvalidität erfolgten Dienstentlassungen bei der Marine in den letzten 20 Jahren auf, die erst im Jahre 1897/98 einen Höhepunkt erreicht haben und seither allerdings eine deutlich fallende Tendenz zeigen.

Demgegenüber lassen die Entlassungskurven bei der Armee eine grösser Beständigkeit und Gleichmässigkeit erkennen. Zwar haben die Entlassungen ebenfalls eine Zunahme, besonders bei den Invaliden erfahren, aber die Steigerung bewegt sich in viel mässigeren Grenzen als bei der Marine. Auch bei der Armee waren die Entlassungen am zahlreichsten im Jahre 1897/98. Während aber der Abgang dieses Jahres wegen Dienstunbrauchbarkeit bei der Marine sich gegen denjenigen z. B. des Jahres 1880/81 vervierfacht hat, ist derselbe bei der Armee seit diesem Jahre nur um $1 / 4(25 \mathrm{pCt}$.) gestiegen. Die Entlassungen wegen Invalidität haben sich in der Marine in demselben Zeitabschnitt sogar versechsfacht, in der Armee allerdings auch beinahe verdreifacht. Dieses auffallend starke Anwachsen der Entlassungen bei der Marine hatte zur Folge, dass seit dem Jahre 1894/95 ihre bis dahin geringeren Abgangsziffern diejenigen der Armee weit überflügelten. In dem Jahre cles Höhepunktes der Entlassungen 1897/98 kamen auf 10 Dienstunbrauchbare bei der Armee 16 bei der Marine und ebenso stellte sich das Verhältniss bei den Invaliden. Seither haben sich diese Verhältnisse für die Marine wieder etwas günstiger gestaltet, indem im letzten Berichtsjahr 1900/01 10 Dienstunbrauchbaren der Armee 14 der Marine und 10 Invaliden der Armee 12,3 der Marine gegenüberstanden. Das Verhältniss der Dienstunbrauchbaren zu den Ganzinvaliden überhaupt gestaltete sich so, dass in der Marine auf 2,4 bis 4,4 Dienstunbrauchbare 1 Invalide und in der Armee schon anf 2,2 bis 3,9 Dienstunbrauchbare 1 Invalide auf den Durchschnitt der letzten 20 Jahre berechnet kommt.

Für den Zweck unserer Betrachtung kommt es nun darauf an, zu untersuchen und festzustellen, welchen Antheil die Geisteskrankheiten und verwandte Zustände an dem Abgang durch Dienstunbrauchbarkeit und Invalidität stellen und welchen Einfluss dieselben auf die starke Zunahme dieses Abganges ausgeübt haben. In der Kurventafel IV sind die Ziffern der wegen Geisteskrankheiten als dienstunbrauchbar Entlassenen der Armee denen der Marine gegenübergestellt. Die Tafel zeigt an, wie viel von 1000 der Kopfstärke wegen Geisteskrankheiten dienstunbrauchbar geworden sind. Sie lässt für die Armee ebenso wie die Kurve der Geisteskranken (s. Tafel I) ein langsames, ziemlich stetiges und gleichmässiges Ansteigen erkennen und weist nach, dass die 
Zahl der bei der Armee wegen Geisteskrankheiten als dienstunbrauchbar Entlassenen sich in den letzten 20 Jahren unter geringen Schwankungen mehr als verdoppelt hat.

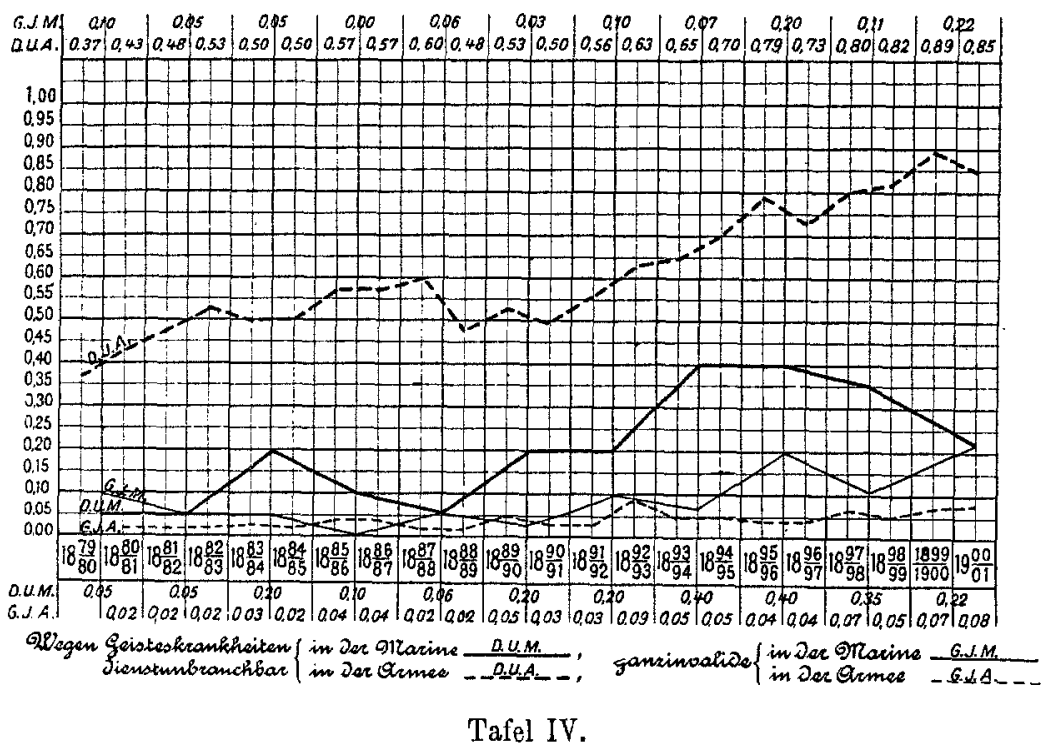

Bei der Marine liegen die Verhältnisse etwas anders. Hicr haben die betreffenden Entlassungswerthe in dem gleichen Zeitraum niemals die Höhe derjenigen der Armee crreicht und betrugen zumeist sogar nicht einmal die Hälfte derselben. Eine erhebliche Zunahme ist aber auch hier zu constatiren, indess ist die Tendenz ungleichmässiger und schwankender. Nachdem in der Nitte der 90er Jahre nach langsamem Ansteigen mit 0,4 pll. ein'Höhepunkt erreicht war, bewegt sich seither die Kurve wieder in absteigender Linie und hat im letzten Berichtszeitraum 1899/1901 mit 0,22 pll. fast $1 / 4$ des Werthes in der Armee mit 0,87 pll. betragen. Auf den ganzen. Durchschnitt der letzten 20 Jahre seit 1881/82, berechnet, stellt sich das Verhältniss so, dass 0,64 pll. der Kopfstärke Dienstunbrauchbarkeitsentlassungen bei der Armee nur 0,22 pM. der Marine gegenüberstehen. Die Geisteskrankheiten sind demach an diesen Entlassungen bei der Armee fast dreimal so stark betheiligt als in der Marine. Dieses für die Marine sehr günstige Bild stellt sich noch deutlicher als solches dar, wenn wir die absolute Zahl der wegen Geisteskrankheiten als dienstunbrauchbar Entlassenen in Vergleich setzen zu der absoluten Zahl überhaupt ailer Dienstunbrauchbaren. Dieses Verbältniss, welches ausdrückt, wie viel 
von 1000 Dienstunbrauchbaren allein wegen Geisteskrankheiten dienstunbrauchbar wurden, giebt die Kurventafel $V$ wieder. In dem ersten Viertel des 20jährigen Zeitraumes von 1881/82 an kamen auf 1000

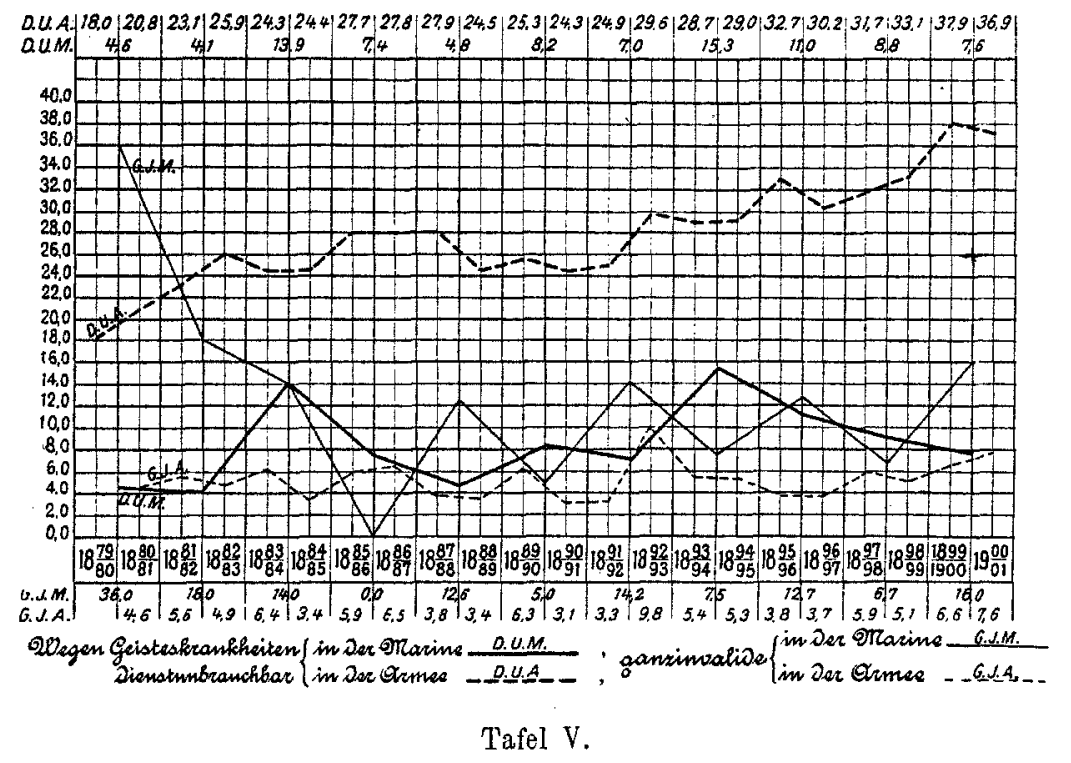

Dienstunbrauchbare der Armee jährlich 25, im zweiten 26, im dritten 30 und im letzten Viertel 34 , bei denen die Unbrauchbarkeit wegen Geisteskrankheiten ausgesprochen war. Es hat also die Zahl dieser Entlassungen eine gleichmëssige Vermehrung erfahren und zwar um nicht ganz die Hälfte, oder mit anderen Worten, - unter den zur Dienstunbrauchbarkeit führenden Erkrankungen weisen die Geisteskrankheiten bei der Armee einen langsam und gleichmässig wachsenden Antheil anf.

Anders bei der Marine. Unter den gleichen Gesichtspunkten, wic oben betrachtet, ist hier die Zahl der wegen Geisteskrankheiten Entlassenen wiederum nicht nur eine bedeutend geringere, sondern sie zeigt auch durchaus nicht die zunehmende Tendenz. Anstatt der für die Armee ermittelten 25, 26, 30 und 34 Geisteskranken unter 1000 Dienstunbrauchkaren wurden in der Marine in denselben vier aufeinanderfolgenden Jabirfünften nur $8,6,10$ und 8 Geisteskranke entlassen. Aus diesen Gegenüberstellungen geht klar hervor, dass die Marine bezüglich der Häufigkeit der.wegen Geisteskrankheiten erfolgten Dienstunbrauchbarkeitsentlassungen bedeutend günstiger dasteht als die Armee, indem hier die Frequenz dieser Abgänge durchschnittlich das Drei- bis Vierfache derjenigen in der Marine ausmacht. Sehr wichtig und bedeu- 
tungsvoll ist endlich der gelungene Nachweis, dass bei der Marine im Gegensatz zur Armee keine Vermehrung der wegen Geisteskrankheit Entlassenen im Verhältniss zur Gesammtzahl der Verluste durch Dienstunbrauchbarkeit stattgefunden hat. Denn es erhellt daraus, dass an dem enormen Anwachsen dieser Verluste die durch Geisteskrankheiten hervorgerufenen in keiner Weise betheiligt sind.

In gleicher Weise wie die Abgänge in Folge Dienstunbrauchbarkeit interessiren uns die durch Geisteskrankheiten bedingten Entlassungen als Ganzinvalide. Während bei den fast ausnahmslos gleich in den ersten Ionaten nach dem Diensteintritt erfolgten Dienstunbrauchbarkeitsentlassungen ein schädigender Einfluss des Dienstes auf den Ausbruch der Geisteskrankheiten nicht $z \mathfrak{u}$ constatiren ist, wird bei den Invalidenentlassungen diesen Einwirkungen eine auf äussere oder innere Schädigung beruhende Schuld an der Entstehung geistiger Störungen beigemessen. Da diese schädigenden Einfüsse einer gewissen Zeit bedürfen, um ihre Wirksamkeit zu entfalten und zur Geltung zu bringen, wird man es verständlich finden, dass die Entlassungen in Folge Invalidität hauptsächlich in die spätere Dienstzeit fallen und daber vorzugsweise ältere Mannschaften und mehr noch Personen des Unteroffizierstandes betreffen. Ueber das Verhältniss und das Auwachsen der Gesammtabgänge in Folge Invalidität in Marine oder Armee ist bereits oben gesprochen worden. Den Antheil der Geisteskrankheiten an diesen Entlassungen stellt die Kurventafel IV dar. Aus derselben geht hervor, dass bei den Invalidisirungen in der Marine, berechnet auf 1000 der Iststärke, Geisteskrankheiten nicht nur eine bedeutend stärkere Betheiligung aufweisen, sondern dass auch die Zahl der deswegen Invalidisirten in viel schnellerem Tempo anwächst als in der Armee. Während des 20 jährigen Zeitranmes seit 1881/82 hat sich nämlich die Zahl dieser Abgänge in der Marine vervierfacht, im Heere dagegen nur verdoppelt. Hier ging auch die Znnahme in ziemlich gleichmässiger Weise von statten, dort aber gestaltete, sie sich zumal im letzten Jahrzehnt ausserordentlich schnell. Denn während im Durchschnitt der ersten zehn Jahre sich die Anzahl der Marineinvaliden zu den Armeeinvaliden verhielt wie $4: 3$, verschob sich dieses Verhältniss im zweiten Jahrzehnt zu Ungunsten der Marine auf $6: 3$ und ist in den allerletzten Jahre sogar noch ungünstiger für dieselbe geworden.

Invalidisirungen wegen Geisteskrankheiten erfolgten demuach auf 1000 der Iststärke in der Marine im Gesammtdurchschnitt der letzten 20 Jahre doppelt so häufig und haben ungefähr doppelt so schnell zugenommen, wie in der Armee, 
Ein etwas verändertes und für die Marine weniger ungünstiges Aussehen gewinnen diese Verhältnisse, wenn man berechnet, bei wie vielen von 1000 Ganzinvaliden die Entlassung durch Geisteskrankheiten verursacht war, den für die Marine gefundenen Werthen diejenigen der Armee gegenüberstellt und dann die Frage beantwortet, $a b$ und in welchem Maasse sich die Geisteskrankheiten an dem Anwachsen des Abganges durch Invalidität der beiden Wehrgattungen betheiligen. Die Kurventafel V belehrt darüber, bei wievielen von 1000 die Ganzinvalidität wegen Geisteskrankheiten ausgesprochen war. Auf den Durchschnitt der vier letzten seit 1881/82 auf einander folgenden Jahrfünfte berechnet, ergiebt sich für die Armee, dass jährlich je $5,2,4,8,5,5$ 5,8 von 1000 Ganzinvaliden allein wegen Geisteskrankheit invalidisirt wurden. Bei der Marine gelangten in denselben Zeiträumen von 1000 Invaliden je 13, 7, 10, 10 Mann wegen Geisteskranken zur Entlassung. Auf den Gesammtdurchschnitt dieser 20 Jahre berechnet kamen also auf 10 geisteskranke Invalide der Marine, nur 5,3 von 1000 bei der Armee, oder die Invalidisirungen wegen Geisteskrankheiten bei der Marine überwogen diejenigen der Armee um fast das Doppelte. Hierdurch wird das günstige Verhältniss, welches in der Marine für die aus gleicher Ursache als dienstunbrauchbar Entlassenen bestand, zum Theil wieder ausgeglichen. Ebensowenig wie für diese letzteren ist auch für die als invalide Entlassenen der Marine trotz der ungleichmässigen Jahresdurchschnittswerthe eine Zunahme zu constatiren, wobl aber bei der Armec, wenn auch in ganz unerhoblichem Maasse. Jedenfalls steht die wichtige Thatsache fest, dass trotz der doppelt so starken Betheiligung der Geisteskrankheiten an den Invalidenentlassungen der Harine gegenüber der Armee bei beiden Wehrgattungen diese Erkrankungen auf das starke Anwachsen des. Gesammtabganges in Folge Invalidität zumal in der Narine gänzlich ohne Einfluss waren. Es verdient hier wiederholt zu werden, dass dieselbe Thatsache bezüglich der aus gleichem Grunde erfolgten Dienstunbrauchbarkeitsentlassungen, constatirt werden konnte. Eine gewisse Einschränkung muss allerdings für die letzten 4 Berichtsjahre seit 1897/98 insofern gemacht werden, als bei der Marine der seither eingetretenen Verringerung des Gesammtabganges in Folge Ganzinvalidität gegenüber eine deutliche Vermehrung der wegen Geisteskrankheiten Invalidisirten eingetreten ist. Dasselbe gilt in etwas geringerem Maasse für die Dienstunbrauchbarkeitsentlasssungen in der Armee.

In der folgenden Tabelle sind die für den Abgang durch Dienstunbrauchbarkeit und Invalidität bei der Marine und der Armee ermittelten Werthe noch einmal übersichtlich zusammengestellt, 
Von 1000 aus dem Dienste Entlassenen wurden jährlich wegen Geisteskrankheiten im Durchschnitt der Jahre

\begin{tabular}{|c|c|c|c|c|c|}
\hline & $\begin{array}{l}1881 / 82 \\
\mathrm{bis} \\
1885 / 86\end{array}$ & $\begin{array}{l}1886 / 87 \\
\text { bis } \\
1890 / 91\end{array}$ & $\begin{array}{l}1891 / 92 \\
\text { bis } \\
1895 / 96\end{array}$ & $\begin{array}{l}1896 / 97 \\
\text { bis } \\
1900 / 01\end{array}$ & $\begin{array}{l}1881 / 82 \\
\text { bis } \\
1900 / 01\end{array}$ \\
\hline In der $\int \begin{array}{l}\text { dienstunbraucbbar } \\
\text { ganzinvalide . . }\end{array}$ & $\begin{array}{r}S \\
13\end{array}$ & $\begin{array}{l}6 \\
7\end{array}$ & $\begin{array}{l}10 \\
10\end{array}$ & $\begin{array}{r}8 \\
10\end{array}$ & $\begin{array}{r}8 \\
10\end{array}$ \\
\hline Summa. & 21 & 13 & 20 & 18 & 18 \\
\hline In der $\left\{\begin{array}{l}\text { dienstunbrauchbar } \\
\text { ganzinvalide }\end{array}\right.$ & $\stackrel{25}{5,2}$ & $\begin{array}{r}26 \\
4,8\end{array}$ & $\stackrel{30}{5,5}$ & $\begin{array}{r}34 \\
5,8\end{array}$ & $\begin{array}{r}28,8 \\
5,3\end{array}$ \\
\hline Summa . & 30,2 & 30,8 & 35,5 & 39,8 & 34,1 \\
\hline Mithin Armee mehr als Marine & 9,2 & 17,8 & 15,5 & 21,8 & 16,1 \\
\hline
\end{tabular}

Diese Tabelle giebt auch die Gesamtsumme der bei der Marine und der Armee wegen Geisteskrankheiten Entlassenen wieder, also Dienstunbranchbare + Ganzinvalide. Die Gesamtzall dieser Entlassungen, auf den Durchschnitt des ganzen 20 jährigen Zeitraumes berechnet, betrug demnach bei der Armee mit 34,1 pll. fast das Doppelte derjenigen in der Marine mit $18 \mathrm{pll}$. jülurlich. Für diese wegen Geisteskrankheiten erfolgten Gesamtentlassungen ist bei der Armce ausserdem noch ein deutliches und gleichmässiges Anwachsen nachweisbar, welches im letzten Jahrfünft gegeniiber dem ersten beinahe $1 / 3$ betrug und auf 1000 der Iststïke berechnet, sogar 3/5. Da aber die Gesamtverluste der Armee durch Dienstunbrauchbarkeit + Ganzinvalidisirung sich in den erwähnten 4 Jahrfünften nur knapp um $1 / 3$ vermehrt haben, so . ergiebt sich aus diesem allerdings geringen Unterschiede die immerhin nicht unwichtige Thatsache, dass in der Armee an dem Anwachsen des Gesamtabganges in Folge Dienstunlorauchbarkeitserklärung und Ganzinvalidisirung die Zunahme der wegen Geisteskrankheiten erfolgten Entlassungen einen nicht unerheblichen Theil der Schuld triigt. Die hohe Wahrscheinlichkeit dieses Verhaltens findet auch in der durch die Kurventafel I veranschaulichten deutlichen Zunahme der Hänfigkeit der an Geisteskrankheiten in der Armee Behandelten eine augenfüllige Bestätigung.

Wie gestalten sich demgegenüber die analogen Verhältnisse bei der Harine? Hier gelangen wir bei einer Gegenüberstellung des durch Geisteskrankheit bedingten Abganges einerseits und des Gesamtabganges andererseits, auf 1000 der Iststärke für dieselben 4 aufeinander- 
folgenden Jahrfünfte berechnet, zu dem Resultat, dass das Anwachsen der wegon Geisteskrankheiten erfolgten Dienstunbrauchbarkeitsentlassungen und Invalidisirumgen weniger stark war als die Zunahme der Gesamtentlassungen überhaupt. Einer Vermehrung der ersteren im letzten Jahrfünft gegenüber dem ersten um genau das Dreifache steht eine solche des Gesamtabganges um mehr als das Dreifache (genau 3,2 fache) gegenüber. Die Zunahme der Geistaskrankheiten war dem. nach in der Marine nicht nur unschuldig an der Steigerung des Gesamtverlustes durch Dienstunbrauchbarkeits- und Invalidenentlassungen, sondern ihr Ansteigen hat mit dem Anwachsen der letzteren nicht eillmal gleichen Schritt gehalten.

Die für die eben erwähnten Resultate maassgebenden Zahlenwerthe sind in der folgenden Tabelle übersichtlich zusammengestellt.

Von 1000 der Kopfstärke wurden jährlich dienstunbrauchbar und invalide im Durchschnitt der Jahre:

\begin{tabular}{|c|c|c|c|c|c|}
\hline & $\begin{array}{l}1881 / 82 \\
\text { bis } \\
1885 / 86\end{array}$ & $\begin{array}{c}1886 / 87 \\
\text { bis } \\
1890 / 91\end{array}$ & $\begin{array}{l}1891 / 92 \\
\text { bis } \\
1895 / 96\end{array}$ & $\begin{array}{l}1896 / 97 \\
\text { bis } \\
1900 / 01\end{array}$ & $\begin{array}{l}1881 / 82 \\
\text { bis } \\
1900 / 01\end{array}$ \\
\hline 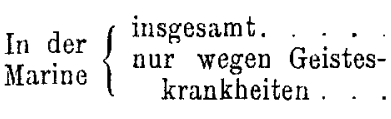 & $\begin{array}{r}15,8 \\
0,16\end{array}$ & $\begin{array}{r}21,4 \\
0,16\end{array}$ & $\begin{array}{r}35,0 \\
0,43\end{array}$ & $\begin{array}{l}51,2 \\
0,48\end{array}$ & $\begin{array}{r}30,9 \\
0,31\end{array}$ \\
\hline 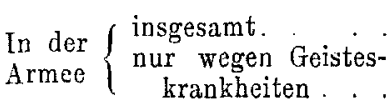 & $\begin{array}{r}25,9 \\
0,54\end{array}$ & $\begin{array}{l}27,7 \\
0,57\end{array}$ & $\begin{array}{l}32,8 \\
0,72\end{array}$ & $\begin{array}{l}35,1 \\
0,88\end{array}$ & $\begin{array}{l}30,4 \\
0,68\end{array}$ \\
\hline
\end{tabular}

Es sei noch mit einigen Worten auf die Hüufigkeit der wegen „Gehirn-, Rückenmarks- und Nervenleiden" erfolgten Dienstunbrauchbarkeitserklärungen und Invalidisirungen in der Marine hingewiesen, weil unter den diese Entlassungen begründenden Leiden die gerade bei der Marine in den letzten Jahren so besonders häufig aufgetretenen Formen der neurasthenischen und hysterischen Erkrankungen sich wiederfinden und einen nicht unwesentlichen Einfluss auf die starke Steigerung dieses Abganges ausüben. Auf das rapide Anwachsen dieser Krankheitsformen, welche häufig mit seelischen Störungen einhergehen oder den als solchen unerkannten Beginn eines ernsteren seelischen Leidens darstellen, wurde bereits bei der Erörterung der Frequenz dieser Art von Erkrankungen hingewiesen. In Uebereinstimmung mit dieser Zunahme ist auch die Zahl der bei der Marine wegen "Gehirn-, Rückenmarks-, und Nervenleiden" dienstunbrauchbar gewordenen, berechnet auf 1000 der Iststärke, ganz enorm gewachsen. Die niedrigen Werthe 
der 80 er Jahre von $0,05 \mathrm{pM}$. bis $0,2 \mathrm{pMI}$. haben sich nämlich fast verfüuffacht gegenüber den Durchschnittswerthen der 90 er Jahre, welche 0,4 bis 0,9 pll. betrugen. Einen Höhepunkt erreichten diese Entlassungen im Berichtszeitraum $1897 / 99$ mit $0,92 \mathrm{pH}$., um im letzten Zeitraum 1899/1901 wieder auf $0,60 \mathrm{pM}$. abzufallen. Auch auf die absolute Zunahme der gesammten Dienstunbrauchbarkeitsentlassungen waren sie von Einfluss, denn, auf. je 1000 derselben selbst berechnet, ergiebt sich eine allerdings geringere Vermehrung. Wenn in den 80 er Jahren von 1000 Dienstunbrauchbaren jährlich durchschnittlich 6,6 wegen Gehirn, Rückenmarks- und Nervenleiden entlassen wurden, so betrug diese Ziffer das 21/2 fache. Der Antheil der Neurasthenie an diesen Werthen ist natürlich nur schätzungsweise zu ermittelu, er belaiuft sich sicher auf ein Drittel, wenn nicht auf ein Halb der erwähnten Entlassungsziffern. Diesen relativ immerhin niedrigen Werthen stehen bedeutend höhere Durchschnittsziffern der aus gleichen Ursachen entlassenen Ganzinvaliden gegenüber. Zwar hat sich deren Zahl in den letzten 20 Jahren, auf 1000 der Iststärke berechnet, fast un das Dreifache vermehrt und zwar stetig und regelmässig, doch ist nicht nur keine Vermebrung ihres Antheils auf 1000 aller Ganzinvaliden zu constatiren, wie bei den aus gleichem Grunde erfolgten Dienstunbrauchbarkeitsentlassungen, sondern vielmelr eine geringe Abnahme, indem im ersten Jahrzehnt 37,2 pH., im zweiten aber nur $32,7 \mathrm{pH}$. aller Invaliden aus obigen Gründen invalidisirt wurden. Wenn also auch die Annahme berechtigt ist, dass die schädigenden Einflüsse des Marinedienstes auf die absolute Höhe dieser Invalidisirungen von bestimmendem Einflusse gewesen siud, so haben sie wenigstens nicht eine wachsende Zumahme derselben im Gefolge gehabt. Während im ersten Jahrzehnt durchschnittlich jahrlich auf 6 Ganzinvalide 1 Dienstunbrauchbarer wegen Gehirn-, Rückenmarks-, und Nervenleiden zur Entlassung $\mathrm{k}: \mathrm{m}$, stellte sich dieses Verhätniss in zweiten Jahrzehnt auf $2: 1$, eine Verschiebung, welche, wie aus dem oben Gesagten hervorgeht, ledig. lich durch die stärkere Zunahme der Dienstunbrauchbarkeitsentlassungen verursacht wurde (s. Tafel VI und VII).

Vergleiche mit den bei der Armee wegen „ehronischer Gehirn- oder Rückenmarkskrankheiten, sowie chronischer Nerveuleiden ernster Art" als dienstunbrauchbar und ganzinvalide Entlassenen und den aus ähnlichen Ursachen bei der Marine in Abgang Gelangten können nur mit grosser Vorsicht angestellt werden, da die statistischen Aufstellungen nicht nach einheitlichen Gesichtspunkten geordnet sind.

Fine bisher bei allen hier aufgestellten Statistiken gemachte Beobachtung kehrt auch jetzt wieder. Die in der Armee gewomnenen Zah- 


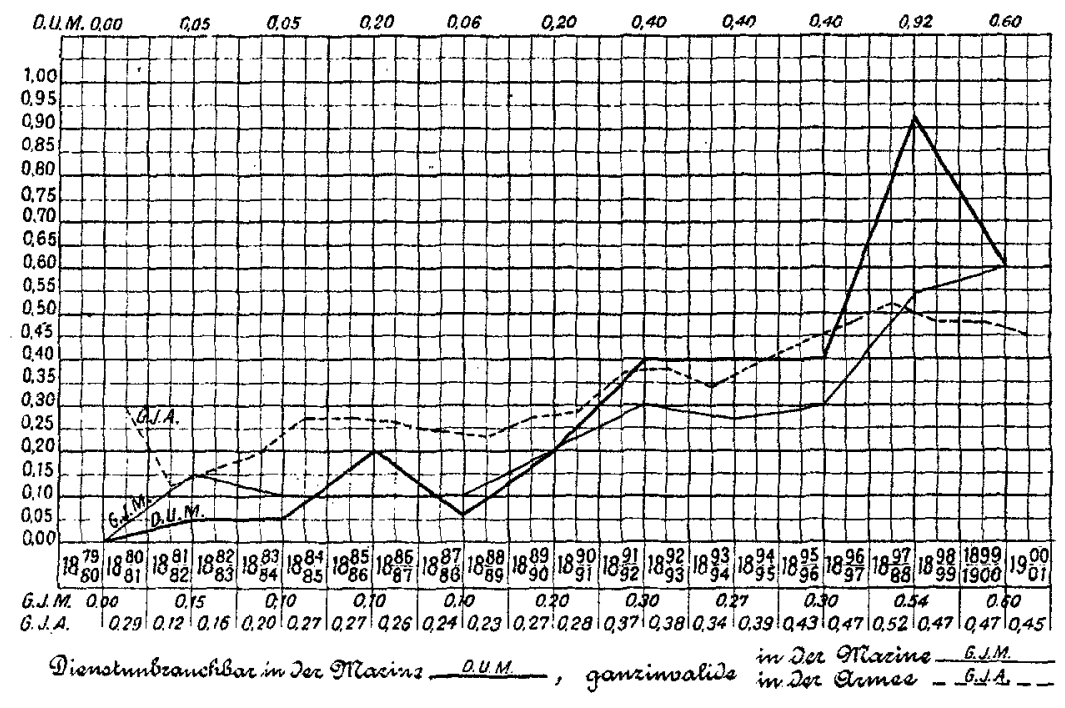

Tafel VI.

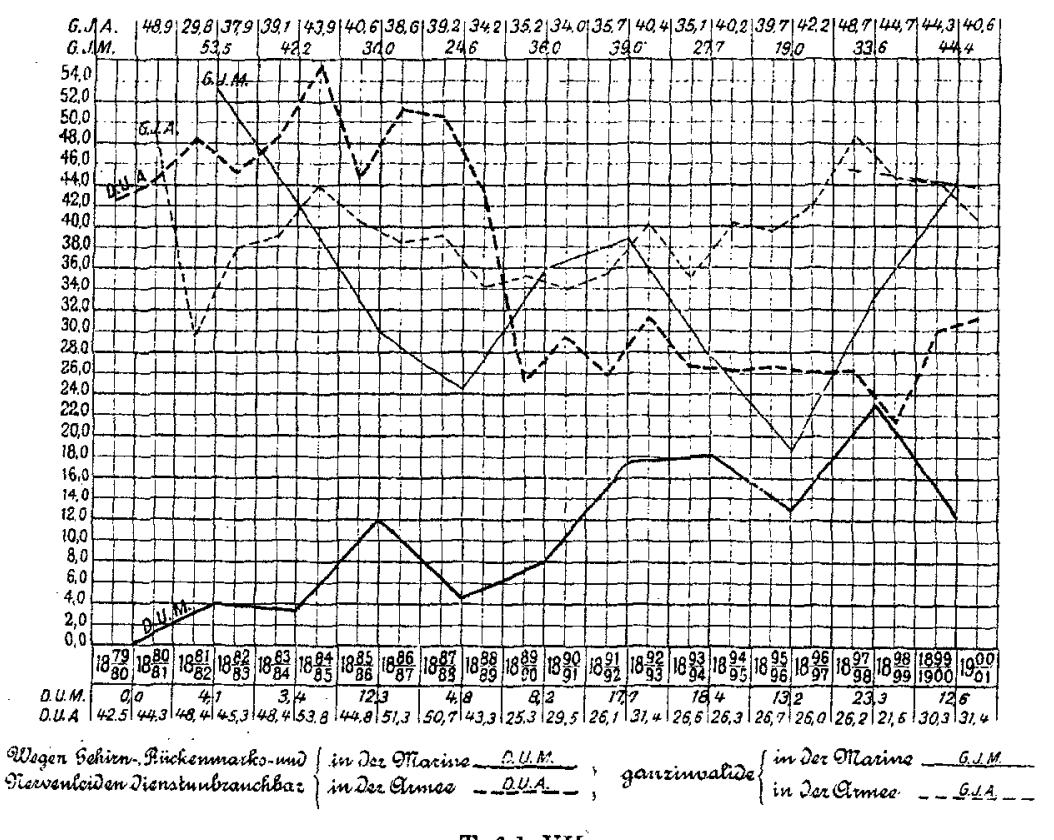

Tafel VII. 
lenwerthe sind bedeutend gleichmässiger und nicht den grossen Schwankungen unterworfen, wie die für die Marine ermittelten. Für solche auf statistischer Grundlage beruhenden Beurtheilungen und Schlussfolgerungen haben natürlich diejenigen Aufstellungen einen grösseren Werth, welche bei geringeren Schwankungen eine möglichst gleichmässige und stetige Tendenz der Veränderung zeigen. Je grösser, zahlreicher und umfassender die Grundlagen sind, auf denen sich die Statistik aufbaut, um so gleichförmiger werden die für gleiche Zeiträume ermittelten Werthe sein, da das umfangreichere Material schon in kürzeren Perioden Gelegenheit zum Ausgleich bietet. So liegen die Verhältnisse bei der Armee; anders bei der Marine. Die hier statistisch ermittelten Durchschnitswerthe sind ans bedeutend kleinerem und wenig umfassendem Material gewonnen, die jährlichen Aufstellungen weisen grosse Schwankungen und Verschiebungen auf, denn die relativ kleinen Ziffern gleichen sich in kurzen Zeiträumen nur wenig aus, und eine bestimmte gleichmässigere Tendenz lässt sicb erst durch die zusammenfassende Beurtheilung lïngerer Zeitperioden statistisch nachweisen. Unter dieser Reserve sind die meisten für die Marine aufgestellten Statistiken zụ betrachten, zumal wenn man die in relativ kurzer Zeit erfolgte enorme Vermehrung des in unserer aufstrebenden Marine dienenden Personals berücksichtigt. Betrug doch die der Zahlenberechnung für das Jahr 1900/01 zu Grunde liegende Kopfstärke von rund 30000 (genan 29005) Namn einschliesslich der an Bord befindlichen Offiziere, Deckoffiziere und Beamten fast genau das Dreifache der Kopfstärke des 20 Jahre zurückliegenden Berichtsjahres 1880/81 mit rund 10000 (genau 0885) Mann.

Wie gesagt weisen die bei der Armee zu Dienstunbrauchbarkeitserklärungen und Invalidisirungen führenden chronischen Gehirn-, Rückenmarks- und Nervenleiden bezüglich ihrer Hïutigkeit nur geringe Unterschiede auf. Die Zahl der wegen dieser Leiden Invalidisirten entspricht ungefälir der der Marine, lässt aber eine geringe Zunahme erkennen, die an Höhe ungefähr der für die Marine constatirten Abnahme gleichkommt. Grösser ist der Unterschied bei den Dienstunbrauchbarkeitsentlassungen in der Armee. Der erwähnten Zunahme in der Marine von 6,6 pII. auf $17 \mathrm{plI}$. aller Dienstunbrauchbaren steht eine Abnabme von 44,1 pll. auf 27,3 pll. im Durchschnitt von $10 \mathrm{zu} 10$ Jahren seit 1880/81 in der Armee gegenüber. Bemerkenswerth ist der enorme Unterschied zwischen diesen Entlassungen bei beiden Wehrgattungen, sowie die fallende Tendenz der hohen Durchschnittswerthe der Armee entgegen der steigenden Tendenz der niedrigen Werthe in der Harine.

Die in den niedrigen Entlassungszifferı zum Ausdruck gelangende 
günstigere Stellung der Marine ist meines Erachtens dadurch bedingt, dass die hauptsächlichsten Rekrutirungsbezirke derselben an den Seeküsten im Allgemeinen in Bezug auf die Disposition zu nervösen Erkranlungen den besten und widerstandsfähigsten Ersatz liefern. Die hohen Ziffern der Armee erfaluren durch die mit immer grösserem Nachdruck geforderte und mit wachsendem Erfolge durchgeführte bessere und vorsichtigere Auswahl der Mannschaften eine stete Abnahme. Das stärkere Anwachsen der niedrigen Werthe bei der Marine aber erklärt sich dadurch, dass in Folge der starken Personalvermehrung nicht melır das Mannschaftsmaterial von den gesunden Rekrutirungsgegenden der Seeküsten überwiegend, sondern in langsam stärker werdendem Maasse auch aus Ersatzbezirken bezogen werden muss, deren Bevölkerung, wie z. B. die vorwiegend mit slavischer Rasse durchsetzten Gegenden, eine hüufigere Veranlagung zu nervösen Erkrankungen erkennen lassen.

In nachstehender Tabelle sind die oben erwalnten Entlassungsziffern noch einmal übersichtlich zusammengestellt.

Von 1000 Entlassenen wurden wegen Gehirn-, Rückenmarks- und Nervenleiden entlassen

\begin{tabular}{|c|c|c|c|}
\hline & \multicolumn{3}{|c|}{ im Durchschnitt der Jahre } \\
\hline & $\begin{array}{l}1881 / 82 \\
\text { bis } \\
1890 / 91\end{array}$ & $\begin{array}{l}1891 / 92 \\
\text { bis } \\
1900 / 01\end{array}$ & $\begin{array}{c}1881 / S 2 \\
\text { bis } \\
1900 / 01\end{array}$ \\
\hline als dienstunbrauchir $\left\{\begin{array}{l}\text { in der Marine } \\
\text { in der Armee }\end{array}\right.$ & $\begin{array}{r}6,6 \\
44,1\end{array}$ & $\begin{array}{l}17,0 \\
27,3\end{array}$ & $\begin{array}{l}11, \mathrm{~S} \\
35,7\end{array}$ \\
\hline als ganzinvalide. $\cdot\left\{\begin{array}{l}\text { in der Marine } \\
\text { in der Armee }\end{array}\right.$. & $\begin{array}{l}37,3 \\
37,3\end{array}$ & $\begin{array}{l}32,7 \\
41,2\end{array}$ & $\begin{array}{l}35,0 \\
39,3\end{array}$ \\
\hline
\end{tabular}

Einen weiteren Maassstab für die Beurtheilung der Hänfigkoit seelilischer Erkrankungen in der Marine, zumal im Vergleich mit der Armee, giebt die Selbstmordstatistik ab. Es unterliegt keinem Zweifel, dass die Solbstmordneigung in sehr innigen Beziehungen $z u$ den seelischen Erkrankungen steht, und dass in der Vlehrzahl der Falle von Selbstmord eine Geistesstörung als Ursache zil betrachten ist. Um aher einen sicheren Aufschluss über die Häufigkeit der Selbstmordneigung und ihre Beziehungen zu seelischen Störungen zu gewinnen, ist es erforderlich, nicht nur die Mortalität durch Selbstmord zu beurtheilen, d. h. den Selbstmordversuch mit tödtlichem Ausgange, sondern es müssen auch die nicht erfolgreichen Selbstmordversuche, also diejenigen, bei denen das Leben erbalten geblieben ist, in den Kreis der Betrach- 
tung gezogen werden. Dadurch nur kann ein sicberes Bild über die Häufigkeit der Selbstmordneigung gewonnen werden.

Ohne hier auf eine genaue Darstellung der einschlägigen Verhältnisse einzugehen, seien nur die Resultate der vergleichenden Selbstmordstatistik zwischen Armee und Marine kurz angeführt. Dieselben ergeben in erster Linie eine wesentlich geringere Betheilignng der Ilarine sowohl an Sterblichkeit durch Selbstmord, als auch an Selbstmordneigung. Die Zahl der Selbstmorde und Selbstmordversuche in der Marine beträgt nämlich wenig mehr als die Hälfte der Fälle bei der Armee, mit anderen Worten, die Selbstmordneigung in der Marine ist ungefähr halb so gross wie in der Armee. Auf die Todesursachen bezogen ist sogar Selbstmord in der Marine nur in $2 / 5$ der Fülle bei der Armee anzutreffen. Bei beiden Wehrgattungen zeigt die Selbmordneigung eine Tendenz des Absinkens, die sich bei der Armee durchaus regelmässig, bei der Marine weniger deutlich und ungleichmässig verfolgen lässt.

Im Gegensatz zur Armee weisen die ersten Nonate des Marinedienstes, ebenso auch noch die ersten Jahre verhältnissmässig recht wenig Selbstmordfälle auf. Schädigende Einflïsse des Marinedienstes machen sich erst in den späteren Jabren geltend und erscheinen in den Selbstmordstatistiken als solche in Gestalt der stärkeren Betheiligung der älteren Unteroffiziere etc. Die geringere Selbstmordneigung besonders in der ersten Zeit des Marinedienstes entspricht der niedrigeren Zahl der wegen Geisteskrankheiten u. s. w. erfolgten Dienstunbranchbarkeitsentlassungen.

Man ist daher zu der Annahme berechtigt, dass einerseits die grade in der ersten Dienstzeit bei der Armee so häufig zu Selbstmord führenden Störungen des seelischen GJeichgewichtes bei den jungen Mannschaften der Marine seltener zur Beobachtung gelangen, und dass andererseits manche seelische Alterationen, falls sie demmoch aufgetreten sind, hier glücklich und schnell ohne Schaden zu stiften, überwunden werden, welche unter den bei der Landarmee herrschenden Verlıältnissen möglicherweise einen Angriff auf das eigene Leben herbeigeführt oder den Ausbruch einer schwereren Psychose eingeleitet hätten.

Von allen Selbstmordfällen in der Marine entfallen mebr als die Hälfte, nämlich 58 pCt. auf die an Land befindlichen Marinetheile, und von den übrigen 42 pCt. kommt die eine Hälfte auf die Schiffe im Auslande und die andere auf die Schiffe in den heimischen Gewässern. Die beiden letzteren liefern demgemäss noch nicht einmal ebenso viel Selbstmorde und Versuche als die Mannschaften an Land. Berücksichtigt man nun, dass ungefähr die Hälfte der ganzen Kopfstärke sich an 
Land, die andere an Bord befindet, so stellt sich das Vérhältniss für die an Land begangenen Selbstmorde bezüglich ihrer Hüufigkeit ziemlich ungünstig. Die Verhältnisse der an Land befindlichen Marinemannschaften nähern sich aber naturgemäss an meisten denen der Armee, die ja auch bedeutend böhere Selbstmordziffern aufweist. Es kain daher nicht nur nicht von einem ungünstigeren Einfluss des Marinedienstes mit seinen specifischen Eigenthümlichkeiten atuf die Häufigkeit der Selbstmordneigung die Rede sein, sondern man ist umgekehrt berechtigt, die Ursachen der durch die Statistik nachgewiesenen weitaus geringeren Häufigkeit der Selbstmordneigung in der Harine, die noch deutlicher wird, durch die Vertheilung der Selbstmordfalle zu Ungunsten der an Land befindlichen, gerade in den Eigenthümlichkeiten des Ilarinedienstes zu suchen, wie sie uns besonders an Bord der Schiffe entgegentreten. Auch die fernere indirecte Schlussfolgerung liegt nach dem Gesagten nahe, dass der Marinedienst an Bord weniger Gelegenheit zur Ausbildung solcher seelischen Störungen, welche häufig zu Selbstmord führen, bietet als der Dienst beim Heere.

Nachdem so an der Hand der vergleichenden Statistik ein Nachweis über die Hänfigkeit des Vorkommens seelischer Erkrankungen und der damit innig zusammenhängenden Selhstmordneignng versucht und die Frequenz genannter Erkrankungen in Beziehung zı dem durch dieselben bedingten Abgang in Folge von Dienstumbrauchbarkeit, Invalidität und Selbstmord gebracht worden ist, erübrigt noch, den solche Erkrankungen hauptsächlich auslösenden Crsachen bei der Harine unter Vergleich mit den Verhältnissen der Armee auf den Grund zu gehen. Der Satz, dass das Militärleben wohl eine wesentliche Gefahr für den Ausbruch von Geistesstörungen birgt, aber nicht die wirkliche Ursache dieser Störungen ist 1 ), findet auch auf den Dienst bei der Marine eine sinngemässe Anwendung. Doch legt die statistisch nachgewiesene etwas grössere Hänfigkeit seelischer Erkrankungen in der Marine den Gedanken nahe, die speciell für den Marinedienst in Betracht kommenden Verhältnisse einer eingehenden Betrachtung zu unterziehen und nachzuforschen, ob nicht in gewissen dem Marinedienst innewohnenden Eigenthümlichkeiten der Grund für das häufigere Entstehen dieser Erkrankungen zu suchen ist. Wie gesagt konnte durch die Statistik festgestellt werden, dass seelische Erkrankungen in der Marine häufiger zur Beobachtung gelangten, als in der Armee, zwar weniger offenkundig in der Form reiner Geisteskrankheiten, die bei der. Marine nur einen unbedeutend höheren Procentsatz aufweisen, als vielmehr unter der Form

1) Düms, Handbuch der Militärkrankieiten. Bu. III. 
der viel zahlreicheren neurasthenisehen und auch hysterischen Erkrankungen. Trotzdem führten Geisteskrankheiten sowie Gehirn-, Nervenund Rüekenmarkskrankheiten bei der Marine viel weniger häufig zu den zumeist in die früheste Dienstzeit fallenden Dienstunbrauchbarkeitsentlassungen als bei der Armee. Dahingegen konnte die letztere mit viel geringeren Zahlen der wegen derselben Leiden als Ganzinvalide Entlassenen aufwarten. Die Selbstmordneigung war wiederum bei der Marine seltener. Betrachtet man diese scheinbar etwas widerspruchsvollen Resultate etwas genauer, so kann es nicht entgehen, dass die Marine mit ihren Ziffern überall da im Vortheil ist, wo von einer längeren Einwirkung ihres Dienstes noch keine Rede ist. Dies ist der Fall bei den erwälnten Dienstunbraucbbarkeitsentlassungen, sowie bei den ebenfalls grösstentheils in die erste Dienstzeit fallenden Selbstmorden. Andererseits waren Invalidisirungen, welche zumeist erst im späteren Verlauf der Dienstzeit herbeigeführt werden, in der Marine hänfiger, ebenso wie Alkoholvergiftungen und die in Folge gewisser acuter und chronischer Infectionskrankheiten wie die später zu erwïhnende Malaria und Syphilis auftretenden Psychosen. Hier macht also der spätere Verlauf des Marinedienstes einen ungünstigen Einfluss auf die Häufigkeit seelischer Erkrankungen geltend. Es geht demnach schon aus den statistischen Ermittelungen hervor, dass die für die Marine nachzuweisende stärkere Betheiligung an seelischen Erkrankungen in der Hauptsache auf Einflüsse zurückzuführen ist, welche erst relativ spät ihre verderbliche Wirkung entfalten.

Die hauptsächlichsten und schwerwiegendsten Ursachen, welche für die geringere Zahl der wegen Geisteskrankheitẹn und verwandter $\mathrm{Zu}$ stände in der Marine als dienstunbrauchbar Entlassenen sprechen, fallen, wie gesagt, ansammen mit denen, welche fïr die Begrindung der in der Marine selteneren Selbstmordneigung herangezogen werden kömen. Die geringere Frequenz dieser Entlassungen ist darauf zurückzuführen, dass seelische Erkrankungen in der Marine in der ersten Zeit des Dienstes, also speciell während and nach der Ausbildungszeit bei weitem nicht so häufiơ zur Beobachtung und Behandlung kommen, als bei dem Landheer. Der unvermittelte Uebergang zu einer ganz neuen Lebensführung, die neue und ungewohnte Umgebung, das plötzliche Aufhören der freien Selbstbestimmung, der Zwang der absoluten Unterordnung, die neuen und ungewohnten körperlichen Anstrengungen, der dienstliche Verkehr mit Vorgesetzten, der Mangel an Bekannteu und Kameraden, deren Beistand und Hülfe man zur Beherrschung all der neven Ansprüche suchen und begehren möchte, alle diese angegebenen Momente wirken auf den angebenden Seemann trotz der ziemlich älnlichen Ver- 
hältnisse bei der Marine lange nicht in dem ausgesprochenen Maasse, wie auf den Landsoldaten ein. So radical ist der Wechsel der Umgebung, der Thätigkeit, der Anstrengungen und der geistigen Inanspruchnabme bei der Marine doeh selten. Hier hat der junge Rekrut selbst während der kurzen Ausbildungszeit an Land immer die Aussicht auf eine baldige Veränderung. Er kommt an Bord und sei es als Matrose, sei es als Heizer, stets wird er dann Verhältnisse vorfinden, in denen er sich leichter zurechtzufinden weiss, und die an seine seelische Widerstandsfähigkeit zuerst nicht so hobe Anforderungen stellen, wie an den Landsoldaten, der Jahre der gleichen ihm von Anfang an so hart und unangenehm erscheinenden Thätigkeit vor sich sieht. Der Seemann hat sogar an Bord in fast allen Zweigen des Dienstes mehr oder weniger Gelegenheit, seine alte Berufsthätigkeit wieder aufzunehmen oder zu verwerthen, da alle die verschiedenen Specialzweige in erster Linie Kräfte erfordem, welche schon früher in ähnlichen Berufer thätig gewesen waren. Die neuen Verbäitnisse werden in solehem Falle nicht lühmend und abschreckend auf den Geist der jungen Marinerekruten einwirken, sondern im Gegentbeil anregend und interessirend. Seine Thätigkeit geht nicht mechanisch vor sich und gezwungen, sondern wird von Verständniss und Interesse geleitet. Da erscheint es nur vatürlich, dass die immerhin schweren Uebergangszeiten hier leichter überwunden werden und dass die -seelische Störungen auslösenden Ursachen weniger intensiv und weniger bäufig einwirken als bei der Landtruppe.

Leider halten diese günstigen Einflüsse des Marinedienstes nicht lange vor, sondern besclrälnken sich im Allgemeinen nur auf die ersten Monate und vielleicht noch Jahre. Im Gegentheil werden wir im weiteren Verlaufe des Warinelebens manche Gelegenbeiten sich einstellen sehen, welche geeignet sind, häufigere und erheblichere Schädigungen der seelischen Sphäre herbeizuführen, als es bei der Armee der Fall ist. Zu dieser Annahme des häufigeren Vorkommens seelischer Erkrankungen in den späteren Dienstjahren muss schon die Betrachtung der vergleichenden Zusammenstellung über die bei der Marine und bei der Armee wegen Geisteskrankheiten u. s. w. erfolgten Ganzinvalidisirungen führen. Bei diesen letzteren wird im Gegensatz zu den Dienstunbrauchbarkeitsentlassungen angenommen, dass dem Marine- resp. Militärdienst, sei es aus äusseren oder aus inneren Schädigungen, Schuld an der zur Entlassung führenden Erkrankung zu geben ist. Die Amahme solcher Schädigungen bat allerdings mit einer gewissen Reserve zu geschehen, denn bei der äusserst wollwollenden Berüeksichtigung, welche die Geisteskranken hinsichtlich ihrer späteren Versorgung finden, werden die zum Nachweis der Invalidität bestimmungsgemäss nothwendigen dienstlichen 
Schädigungen schon aus humanen Gründen leichter als vorliegend angenommen, als lediglich die ätiologische Begründung es zulassen würde. Vielleicht verdient diese Reserve für die Narine besonders stark betont zu werden. Jedenfalls liefert die vergleichende Statistik für die Marine bedeutend ungünstigere Zahlen bezüglich der wegen Geisteskrankheiten Invalidisirten als die Armee. Es wurde nachgewiesen, dass bei der Armee im Durchschnitt der letzten 20 Jahre erst auf 5 bis 6 Dienstunbrauchbare ein Invalider kam, während bei der Marine die Zahl der wegren Geisteskrankheiten als dienstunbrauchbar Entlassenen annähernd gleich war derjenigen der aus gleichem Grunde Invalidisirten. Im Verhältniss zu den Dienstunbrauchbarkeitserklärungen führten also Geisteskrankheiten in der Marine $6 \mathrm{mal}$ so häufig zur Invalidisirung als bei der Armee. Auch absolut war die Zahl der Ganzinvaliden eine wesentlich höhere bei der Marine, indem dieselbe fast das Doppelte der für die Armee festgestellten Werthe betrug. Schon aus dem Unterschiede dieser Zahlen geht deutlich hervor, dass in der Marine bei einem viel grösseren Theile von Geisteskrankheiten die Entstehung oder Verschlimmerung dieser Leiden in einen ursächlichen Zusammenhang mit den besonderen Eigenthümlichkeiten des Dienstes gebracht worden ist. Dass der Marineangehörige in seinem Berufe überhaupt grösseren und stärkeren Einflüssen ausgesetzt ist, als der Landsoldat, kann keinem Zweifel unterliegen. Wenn aber zu diesen Einwirkungen sich noch andere hinzugesellen, wie lange Seereisen, der Aufenthalt an Bord in tropischen Gegenden, die dadurch bedingte ungewohnte oder weniger bekömmliche Nahrung; geringe Abwechselung, grosse kürperliche Anstrengungen und Strapazen u. s. w., dann werden an sein Nervensystem noch wesentlich stärkere Anforderungen gestellt, als an das des Soldaten im Landheer. Ganz besonders sind es die sich langsam summirenden Eintlüsse, denen schliesslich auch die stärkste Natur unterliegen kann. Dazu kommt noch die bedeutend grössere Gelegenheit, von acuten und chronischen Krankheiten befallen zu werden, denen mit Erfolg zu widerstehen, durch die ungünstigen änsseren Verhältnisse des Klimas, der Unterkunft und der Verpflegung an Bord sehr erschwert wird. Körperliche und geistige Ueberanstrengung z. B., welche in der Landarmee, wenigstens zu Friedenszeiten, nur in sehr seltenen Fällen ein solches Maass erreichen, dass dadurch seelische Erkrankungen hervorgerufen werden, können bei der Marine, zumal in Begleitung von anderen ungünstigen Umständen (s. o.) viel eher eine erhebliche Schädigung des Nervensystems hervolrufen, und wenn, wie das sehr häufig der Fall ist, psychische Aufregungen und Alterationen dazatreten, zu vorübergehenden oder gar clauernden Psy- 
chosen Anlass geben. Die Marine stellt in dieser Hinsicht fast ein Mittelding zwischen den Verhältnissen der Armee zu Friedenszeiten und denen za Kriegszeiten dar.

$\mathrm{Zu}$ den Momenten, welche in Folge der Eigenthümlichkeiten des Dienstes in der Marine besonders häufig Anlass zum Ausbruch von seelischen Erkrankungen geben, gehört in erster Linie der Hitzschlag. Die seelischen Störungen werden hierbei meist eingeleitet mit plötzlich anftretender Bewusstlosigkeit, später treten neben grosser Unruhe, starkem Angstgefühl und Verwirrtheit häufig Gehörs- und Gesichtshallucinationen auf. Zuweilen steigern sich die Erregungen zu Tobsuchtsanfällen. Oft zeigen die Anfälle grosse Aehnlichkeit mit epileptischen Anfällen, mit denen sie häufig verwechselt werden. In den meisten Fällen sind die Störungen schnell vorübergehender Art, ohne weitere Spuren zu hinterlassen; nicht allzuselten ist aber auch die Einwirkung von bleibender Dauer, so dass die Entlassung des Betreffenden erfolgen muss. Naturgemäss kommt der Hitzsehlag am häufigsten an Bord in den tropischen Gegenden des Auslandes vor, wo die gesammte Mannschaft den Einflüssen der Temperatur und der Sonne ziemlich gleichmässig unterworfen ist. Aber auch an Bord der Sehiffe in den heimischen Gewässern gelangt Hitzschlag oft zur Beobachtung; hier giebt vor Allem der anstrengende Dienst des Maschinen- und Heizerpersonals in den überhitzten und schwer ventilirbaren Maschinen- und Heizrätumen der modernen Schiffe zu derartigen Erkrankungen Veranlassung. Es ist auffallend, dass die nach Hitzschlag auftretenden Psychosen oft unter dem Bilde einer schweren Melancholie verlaufen und eine starke Neigung zu Angriffen auf das eigene Leben zeigen. Auch mehr oder weniger leichte geistige Verwirrtheit bleibt zuweilen für längere Zeit zurück. Manche in der Anlage bereits vorhandenen, aber bislang verborgen gebliebenen Geisteskrankheiten, wie die verschiedenen Formen des Schwachsimns, gelangen nach einem Anfall von Hitzschlag zum offenkundigen Ausbruch. Besonders gerne treten derartige seelische Störungen im Gefolge von Hitzschlag ein, wenn körperliche and geistige Ueberanstrengungen, sowie Alkoholmissbrauch ihre Hand mit im Spiele hatten. Ueberhaupt werden von Hitzschlag und seinen Folgen am stärksten diejenigen Mannschaften betroffen, welche erst frisch aus Europa in die Tropen gekommen, noch nicht an die Hitze gewöhnt sind und die Vorboten der Erkrankung aus Unkeuntniss nicht beobachten.

In einer grossen Anzahl seelischer Erkrankungen finden wir als auslösende Momente Unfälle angegeben. Meist handelt es sich um Verletzungen des Schädels, die entweder sofort oder erst später, .zuweilen nach langen Wochen und Monaten solche Störungen im Gefolge 
baben. Bei diesen Erkrankungen kommt der Dienst des Seemanns als Ursache ganz besonders insofern in Betracht, als an seine Thätigkeit bei schlechtem Wetter und stïrmischer See, bei forcirten Falurten, im Manöver u. s. w. hohe Anforderungen gesteilt werden müssen, die ihn sehr häufig äusseren Gefahren aussetzen. In erster Linic sind es Gehirnerschütterungen, meist durch Sturz in die Tiefe entstanden, welche seelische Störungen im Gefolge haben. Es kommen nach Unfall alle möglichen Formen des Irreseins vor, die sich von den nicht traumatisch bedingten durch nichts als durch ihre Aetiologie unterscheiden. Indess befinden sich unter unserem Material nur wenige Fälle, bei denen der Unfall auf psychisch ganz normale, nicht belastete Individuen einwirkte. Die Mehrzahl war belastet, sei es erblich, sei es durch erworbene Schädlichkeiten, besonders Epilepsie, Syphilis und Alkoholismus. Im Ganzen überwiegen auch hier die depressiven und hypochondrischen $\mathrm{Zu}$ stiande; in den Wahnvorstellungen spiclt vielfach der Unfall mit seinen Folgen eine Hauptrolle. Neben epileptiformen Krämpfen treten fermer schwere Benommenleit, Schwäche der Denkkraft, beftige Kopfschmerzen und Schwindelanfälle auf. Einige Male werden T'obsuchtsanfälle speciell nach Kopfverletzungeu erwähnt, seltener wochenlang andauernde Amnesie. Auch das Auftreten von schwerer Melancholie ist nach Kopfverletzungen beobachtet worden. In den letzten Jahrzehnten ist in der Literatur das Auftreten der sogenannten "traumatischen Neurosen" nach Verletzungen, zumal Ersehütterungen des ganzen Körpers häufiger beschrieben worden, nicht selten einhergehend mit Depressionszuständen der seelischen Spbäre, Gedächtnissschwäche und hystero-epileptischen Krampfanfallen. Ein derartiger Fall wird z. B. im Sanitätsbericht der Narine rom Jahre 1883/85 erwähnt, wo ein Mlatrose bei einem Segelmanöver im englischen Canal Nachts über Bord fiel und nach einigen Minuten bewusstlos mit oberflächlicher Athmung und Puls aus dèm Wasser gezogen wurde. Nach dreiviertel Stunden war das Bewusstsein zurückgekebrt, Temperatur $38,2^{\circ}$. Auffallend war am nächsten Morgen das psychische Verhalten des Mannes. Der Gesichtsausdruck war ängstlich, Fragen wurden anf lautes Anrufen hin nur durch schwaches Nicken des Kopfes beantwortet, Nahrung erst uach Zureden genommen. Während die übrigen Erscheinungen sich schnell besserten, schwanden die psycbischen Störungen nur langsam, so dass die Behandlung mehrere Wochen in Anspruch nahm. Ein Rückfall trat nicht wieder auf.

Von mindestens ebenso grosser Bedeutung wie Unfälle sind für die Auslösung seelischer Erkrankungen bei der Marine die Infectionskrankheiten, zumal die im Auslande erworbenen. In erster Linie 
handelt es sich da um die Malaria, die Jahr aus Jahr ein, sei es in Afrika oder in der Sẗdsee, in Ostasien oder in Amerikit ihre Opfer fordert. Die psychischen Störungen als Begleiterscheinung oder als Nachkrankheit von Malaria sind den Tropenärzten wohlbekannt und von ihmen oft beschrieben worden; sie können unter den verschiedensten Bildern auftreten. Wiederum handelt es sich vielfach um melancholische Zustände, we]che sich besonders häufig während langdauernder Reconvalescenz entwickeln. Sie gehen einher mit hochgradiger Schlaflosigkeit und Unvermögen zu geringster geistiger Anstrengung. Zuweilen sind die psychischen Depressionen so heftig, dass die Kranken bei den gleichgiltigsten Anlässen zu weinen beginnen und ihro Affecto nicht bemeistern köunen. Die acuten Affectionen von Seiten des Gehirns während der Krankheit selbst äussem sich nicht selten in Form von maniakalischen Anfälen oder als vorübergehende hallucinatorische Verwirtheit, Auch werden epileptiforme Krampfanfälle und Tage lang andauernde Aphasien erwähnt. Im Sanitätsbericht von 1891/93 heisst es bezïglich der Nalariacomplicationen in Ostafrika "Geistesstörungen während und nach Wechselfieber sollen auf der dentseh-ostafrikanischen Küste und auf der Insel Sansibar häufiger vorkommen. Die Prognose soll bei Europäern im Allgemeinen gut, bei Schwarzen dagegen ungünstig sein und Heilung bei letzteren sehr selten vorkommen". Alle diese Psychosen, so wird ausdrücklich hervorgehoben, sind durch Chinin meist günstig $z \mathfrak{u}$ beeintlussen. In einzelnen Fïllen wird aber auch umgekehrt Cbinin für das Eintreten von seelischen Störungen bei Malaria verantwortlich gemacht, dieselben seien erst nach Aussetzen des Chinin geschwunden. So wird in Sanitätsbericht von 1883/85 ausdrücklich erwähnt, dass unter den üblen Nebenwirkungen des Chinins eiumal vorübergehende hallucinatorische Verrücktheit beobachtet wurde. In anderen Fällen wurde letztere Störung als Erscheinung der Nalaria aufgefasst. Im Sanitätsbericht von 1895/97 heisst es: „Störungen des Nervensystems bei Nalaria gehörten in Ostafrika zu den regelmässigen Erscheinungen des Krankheitsbildes, sie bestanden in Kopfschmerzen, Schlaflosigkeit, psychischer Reizbarkeit und Empfindlichkeit gegen Geräusche, grelles Licht u. s. w. Martin hat Zustände von hochgradiger Nervosität mit ausserordentlicher Empfänglichkeit für Gemüthsaffecte als Erscheinungen latenter Malaria angesprochen. Ebenso wie die Psychosen nach Hitzschlag zeigen auch diejenigen nach Malaria eine anffallende Neigung zum Selbstmord. Im Sanitätsbericht von 1895/97 wird ein Fall erwähnt, wo die Malaria mit einem Anfall von Geistesstörung begann, in welchem der Kranke sich in's Wasser stürzte. Im Lazareth stellte sich hohes Wechselfieber mit Vilzschwellung heraus, 
Nach wenigen Tagen erfolgte Heilung durch Chinin. Obwohl ein grosser Theil dieser bei Malaria auftretenden Psychosen, wenn anch erst nach erfolgter Heimsendung des Kranken in völlige Heilung ïbergeht, so bleiben doch in nicht wenigen Fällen die Störungen so hartnäckig und dauernd, dass sie zu Invalidisirungen führen müssen.

$\mathrm{Zu}$ den Erkrankungen, welche ebenso wie die Malaria bei ihrem epidemischen und endemischen Auftreten im Auslande recht oft einen schweren Verlauf nehmen und während desselben oder in ihrer langwierigen Reconvalescenz von psychischen Störungen, wenn auch nicht so häufig wie die Malaria begleitet sind, gehört die Ruhr. Auch die im Gefolge dieser Erkrankung auftretenden seelischen Veränderungen bestehen fast stets in starker geistiger Depression, die oft Mlonate lang anhält und erst mit der vollständigen Heilung des Grundleidens verschwindet. In vereinzelten Fiallen steigert sich die psychische Depression zu acuter Melancholie mit Wahnvorstellungen, Sinnestäuschungen namentlich solchen des Gehörs und führte sogar zu Selbstmordversuchen. Nicht nur die Ruhr, sondern überhaupt Darmleiden jeder Art, zumal hartnäckige Stuhlverstopfungen, die besonders in der ersten Zeit des Aufenthaltes an Bord recht häufig in Bebandlung kommen und Neigung haben chronisch zu werden, erfordern bezüglich ihres Einflusses auf die Entstehung acuter Psychosen eine erhöhte Aufmerksamkeit. Im Jahresbericht 1900/01 findet sich ein Fall verzeichnet, wo hartnäckige chronische Stuhlverstopfung bei einem Manne, der bisher nie an Epilepsie gelitten hatte und in dessen Familie dieses Leiden niemals aufgetreten war, drei epileptische Anfälle hintereinander auslöste. Die sich über 10 Tage erstreckende Kothverhaltung wich schliesslich Oeleinläufen. Krämpfe baben sich später niemals wieder eingestellt.

Von anderen acuten Infectionskrankheiten spielen Typhus, acuter Gelenkrheumatismus, Pneumonie, Influenza und llasern bei der Aetiologie seelischer Erkrankungen in der Marine eine untergeordnetere Rolle und unterscheiden sich bezüglich der Häufigkeit ihres Einflusses auf die Entstehung von Psychosen nicht wesentlich von den ähnlichen Verhältnissen bei der Armee. Ein interessanter Fall, wo es sich um eine mit einer acuten Geistesstörung beginnende fieberhafte Krankheit handelte, wird im Sanitätsbericht von 1881/82 genauer mitgetheilt. "Ein Heizer war während der Fahrt durch den atlantischen Ocean eines Morgens durch eine Batteriepforte über Bord gesprungen. Die Untersuchung des im bewusstlosen Zustande an Bord Zurückgebrachten ergab Rasselgeräusche über den hinteren unteren Lungenpartien linkerseits. Einige Stunden später betrug die Temperatur 40,20 und schon Nachmittags deutete eine von der Hitte des linken Schulterblattes nach 
abwärts reichende deutliche Dämpfung mit bronchialem Atbmen auf Lungenentzündung. Von Anfang an waren sehr heftige Stirnkopfschmerzen vorhanden. Schon nach 2 Tagen trat unter Temperaturaball die Krisis ein. Das Befinden besserte sich, und nach weiteren 7 Tagen waren dio physikalischen Erscheinungen über beiden Lungen wieder normal. Der Betreffende gab bei seiner Vernehmung an, er sei zur Zeit des Sprunges über Bord besinnungslos gewesen und wisse von dem Vorfall nichts. Da nun festgestellt wurde, dass er kurz vorher schon über Schmerzen und Stiche in der linken Brustbälfte geklagt und da die Krankheitserscheinungen sich ïberhaupt zu schnell entwickelt hatten, um als Folgen des Aufentbaltes im Wasser betrachtet werden zu können, so wurde angenommen, dass hier eine mit dem Beginn einer fieberhaften Erkrankung entstandene acute Geistesstörung vorliege. In der weiteren Reconvalescenz traten noch mehrere psychische Frscheinungen auf, welche eine weitere Beobachtung des Mannes veranlassten. Derselbe war stets niedergeschlagen und apathisch, antwortete auf Fragen nur kurz und verdriesslich und klagte über ab und zu auftretende Kopfschmerzen und Schwindelgefühl. Sein Blick war unfrei und scheu, so dass er den Eindruck eines brütenden Hypochonders oder Melancholikers machte. Während des Aufenthaltes in Kapstadt entzog er sich durch Desertion der weiteren Beobachtung".

Auch nach verhältnissmässig leichten Verletzungen und Erkrankungen wie Gelbsucht, Grippe, gastrisches Fieber, sogar Tripper wurde zuweilen das Auftreten von vorübergehenden seelischen Störungen beobachtet.

Eine besondere Berücksichtigung bei der Frage nach der Aetiologie seelischer Erkrankuugen in der Marine verdienen die Alkoholvergiftungen. Der unheilvolle Einfluss des Alkohols änssert sich hier, wemn auch nicht so häufig als Ursache mannigfacher Seelenstörungen, sondern vielmehr als Symptom einer solchen. Im Allgemeinen tritt der Alkoholismus in den ersten Monaten und Jahren der Dienstzeit seltener auf als in den späteren Jahren. War auch ein kleiner Theil der Rekruten bereits vor dem Diensteintritt dem Schnapsgenuss ergeben, so ist doch die Dauer der schädlichen Einwirkung meist nur erst eine verhältnissmässig kurze gewesen. Dann sind auch die jugendlichen Trinker in der Mehrzahl Gelegenheitstrinker, die sich erst mit dem zunehmenden Alter zu Gewohnheitstrinkern heranbilden. Es ist unzweifelhaft, dass der im Anfange der 20er Jahre besonders starke Hang zum gelegentlichen Trunk in der Geselligkeit des Militärlebens eine günstige Gelegenheit zur Weiterausbildung und Verbreitung findet. Meist handelt es sich bẹ den Trụksüchtigen um Epilepsie oder unm die Form des 
erworbenen Schwachsinnes. Die Trunksucht nimmt bei solchen Indivi-

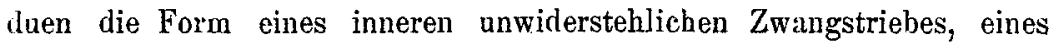
krankhaften Gelïstes an, wie er die Handlungen der meisten Geisteskranken beherrscht. In anderen Fällen treibt die günstige Gelegenbeit, die Verführung nnd die allmälige Gewölnnung die Betreffenden dem Alkobol in die Arme und lässt sie langsam seiner Macht erliegen. Schliesslich sucht mancher im Alkoholgenuss Ruhe und Vergessen von dienstlichen Widerwärtigkeiten und anderen Misshelligkeiten und gelangt unwillkürlich mehr und mehr unter seine Herrschaft. Zeichen geistiger: Störung, welche über die krankhafte Neigung Aufschlıss geben kömnten, bleiben lange Zeit unentdeckt, nur die psychische Anamnese giebt verlässliche Resultate, indem sie entweder die Trunksucht in der nächsten Verwandtschaft als bestehend nachweisen kann oder sonstige Geistesund schwere Nervenkrankheiten, unter diesen besonders die Epilepsie. Nimmt nun bei solchen Individuen die Trunksucht in der Armee schon zuweilen unter den Einflïssen des Soldatenlebens einen so krankhaften Grad an, dass sie sich zur offenkundigen Psyehose entwickelt, so wird dies bei der Marine noch viel leichter möglich erscheinen, wemn man auf die für die Entwicklung der Sucht znm Trunk hier besonders günstigen Umstände hinweist. Grade an Bord der Schiffe spielt bei dem engen Zusammenleben der Mannschaften die Verführung zum Alkoholgenuss eine grosse Rolle. Bleibt aber der Genuss desseiben in den heimischen Gewässern meist in mässigen Grenzen oder zeigt er wenigstens nicht sogleich seine gefährlichen Wirkungen auf die Seele, so treten uns im Auslande, zumal in den tropiscben Gegenden, die Erscheinungen in einem ganz anderen Lichte entgegen. Unter den Einwirkungen grosser Hitze, die ihrerseits nur zu verführerisch zu unmässigem Consum alkoholischer Getrïnke reizt, ist Körper und Geist bedeutend widerstandsloser und erliegt den verderblichen Wirkungen viel schneller und leichter als in den gemässigten Klimaten. Ganz besonders verhängnissvoll macht sich dieser Umstand geltend, wenn noch die schädigenden Einwirkungen dazwischen tretender körperlicher Erkrankungen dazukommen. Wir finden in den Sanitätsberichten eine ganze Reihe von Fällen aufgeführt, wo die Vergesellschaftung von acuten Infectionskrankheiten mit Alkoholismus in den Tropen den ersteren eine viel ungünstigere Prognose verlieh und sehr häufig zu schweren Gehirnerscheinungen führte. In ganz besonderem Maasse triffit dies für die Nlalariaerkrankungen zu, auf deren Bedeutung hinsiclitlich der Aetiologie seelischer Störungen bereits aufmerksnm gemacht worden ist: Ebenso gefährich wird der Aikoholismus den von Hitzschlag Betroffenen. Der Alkohnliker ist den Einwirkungen der Hitze gegenüber meist sehr Archiv f. Psychiatrie. Bd. 40. Heft 3. 
wenig widerstandsfähig, wird daher leichter von Hitzschlag betroffen und zeitigt bedeutend schwerere Erscheinungen von Seiten des Nervensystems als ein sonst Gesunder.

Auch das Missverbältniss zwischen angestrengter Arbeit und nothwendiger körperlicher und geistiger Erholung, der Mangel an Abwechslung und geistiger Ablenknng, ungewohnte oder zu eintönige Nahrung führen leichter dazu, im Genuss von alkoholischen Getrünken alles das, Musse, Erholung, Trost und Befriedigung zu suchen, was die Ungunst der äusseren Verhältnisse versagt.

Hit alle dem soll nicht gesagt seiln, dass bei der Marine del Alkolgenuss überhaupt bedeutend stärker verbreitet oder intensiver sei als bei der Armee. Doch muss es als feststehend gelten, dass in Folge der oben geschilderten Verhältnisse die Trunksucht bei der Marine viel eher zu starken und uachhaltigen Schädigungen ron Körper und Geist führen kann als bei dem Soldaten des Landheeres. Immer spielen aber Vererbung und Disposition, Schwachsimn oder Epilepsie eine gleich mächtige Rolle hinsichtlich des Bodens, auf dem der Alkohol zu besonders verderblichen Folgen Anlass giebt.

In den Marinesanitätsberichten der $70 \mathrm{er}$ Jahre begegnen wir verschiedentlich einer Kritik über die Häufigkeit der Alkoholvergiftungen. So heisst es im Bericht von 1875/76: "Es kam zur Beobachtung ein Fall von chronischer Alkoholvergiftung. Bemerkt sei, dass ansser diesem kein weiterer Fall von chronischem Alkoholmissbrauch in den Berichten der Narineärzte verzeichnet ist".

Für so selten wurde der Alkoholismus in der Marine gehalten, dass dies besonders hervorzuheben berechtigt erschien. Der Bericht des folgenden Jahres führt aus: „Alkoholmissbrauch fübrte nur in vier Fällen zu ärztlicher Behandlung. Hierdurch wird der moraljsche Zustand der Mannschaften als ein sehr guter charakterisirt". Fast mit denselben Worten werden im folgenden Jahresbericht die zur Behandlung gelangten vier Fälle von Alkoholismus begleitet. In diesen so günstig kritisirten Jahren betrug die Durchschnittszahl der an Alkoholvergiftungen Behandelten 0,4 bis 0,5 pM. der gesammten Iststärke der Marine. Seither haben sich diese Werthe gleichmässig bis anf genau die Hälfte 0,20-0,22 pM. vermindert! Wollte man ebenso, wie es in den erwähnten Berichten geschehen ist, an der Hand dieser Ziffern eine Kritik über den heutigen moralischen Zustand der Mannschaften bei der Marine fallen, so mïsste man hiernach den moralischen Zustand fiir doppeit so gut als vor 20 Jahren charakterisiren! Der Armee muss zugestanden werden, dass ihre analogen Ziffern nicht unwesentlich niedriger waren. Sie zeigten ebenfalls, speciell im letzten Jahrzehut eine gleich- 
mässige und deutliche Abnahme und erreichten in den letzten Jahren ibr Nlinimum mit 0,12 pMl. gegenüber dem der Marine mit 0,21 pMl.

$\mathrm{Da}$ der Abnahme dieser zur Behandlung gelangten, also der schwereren Alkoholvergiftungen keine ebensolche Abnahme, sondern im Gegentheil eine Zunahme der Geisteskrankheiten in Heer und Marine entspricht, erscheint der Rückschluss gerechtfertigt, dass für das Anwachsen der Geisteskrankheiten die auf alkoholischer Grundlage entstandenen nicht in besonderem Maasse verantwortlich zu machen sind. Trotzdem müssen wir daran festhalten, dass die an Bord der Schiffe besonders in den tropischen Gebieten wirksamen ungünstigen Einflüsse auf den Organismus des Alkoholikers eine weit verheerendere Einwirkung ausüben, als es bei einem dem Trunke ergebenen Landsoldaten der Fall sein kamn.

In der grössten Mehrzahl sind es naturgemäss ältere Unteroffiziere, die von den Schädigungen des Alkoholismus betroffen werden, und bei denen schon ein mehrjäbriges starkes Potatorium bestand. Die ausgesprochenste Form des alkoholischen Irreseins, die durch das Delirium tremens dargestellt wird, bietet zumal in den heissen Klimaten eine recht ungünstige Prognose. Häufig treten nur Krämpfe und tobsuchtsähnliche Anfälle auf, zuweilen schon nach ganz geringen Wengen Alkohols. Verschiedentlich wird über vorübergehenden liallucinatorischen Wahnsinn berichtet. Alte Unteroffiziere mit ausgeprägten Erscheinungen des chronischen Alkoholismus hatten moralische und Erinnertungsdefecte, Wahnvorstellungen, Schwäche des Intellectes mit beginnender Verblödung und paranoischen Erscheinungen. Auch das häufige Vorkommen der progressiven Paralyse in der Marine steht mit den verderblichen Wirkungen des Alkohols in engem Zusammenhang. In rereinzelten Fällen führten acute Alkoholvergiftungen unter dem Einfluss der Tropenhitze oder directen Sonnenbestrahlung unmittelbar zum Tode.

Von anderen Vergiftungen verursachten solche mit Morphium, Niko. tin, Blei; Jodoform und sogar Oelsardinen hin und wieder schnell rorübergehende seelische Störungen, welche von Tobsuchtsanfällen, Krämpfen, acuter Verwirrtheit u. a. begleitet waren.

Einen ähnlichen unheilvollen Einfluss wie der Alkohol, übt die Syphilis auf die Entstehung mancher seelischer Erkrankungen aus. In häufigen Fällen fübrt sie zu organischen. Veränderungen im Gehirn und davon abhängigen psychischen Störungen. Fine besonders wichtige Rolle spielt die Syphilis bei der Aetiologie der progressiven Paralyse. Für uns hat die Lues bezüglich der Entstehung seelischer Erkrankungen deshalb ein hervorragendes Interesse, als wir bei der Nlarine häufiger Gelegenheit haben, einen schwereren Verlauf der Syphilis zu beobachten, 
als bei der Armee. Scbuld daran sind abgesehen von den ungünstigeren Umständen der Bebandilung und Verpflegung an Bord die häufigen im Auslande, speciell in Ostasien erworbenen Infectionen, deneı nicht mit Unrecht ein besonders schwerer und hartnäckiger Veriauf zugeschrieben wird. Diese auffallend schweren Erscheinungen äussern sich mit Vorliebe in der Betheiligung des Gehirns und dadurch bedingten Stôrungen der seelischen Sphäre. Zuweilen treten sie in der Form des Verfolgungswahns auf. Kopfschmerzen, Ohnmachten, Gedächtnissschwäche, Störungen und Nachlassen der Intelligenz, vor Allem Läbmungen und Sprachstörungen werden selten vermisst. Mehr noch als bei der Armee ist bei der Marine für die verhältnissmässig grosse Anzahl der an Paralyse erkrankten Offiziere voraufgegangene Lues als eine der wichtigsten Trsachen za betrachten, zumal wenn durch die intensivere körperliche und geistige lnanspruchuahme und durch die Lebensweise an sich schon die Disposition zu nervösen Erkranknngen erhoht ist. Obwohl in Grossen und Ganzen ausser bei der Paralyse die Prognose der im Gefolge von Syphilis auftretenden psychischen E Erkrankungen keine ungünstige ist, so führen sie doch in nicht wenigen Eällen in Folge der sich an sie anschliessenden allgemeinen Erschöpfungs- und Schwächezustände oder der durch sie bedingten Neurasthenie zu späteren Invalidisirungen. Es muss stets berücksichtigt werden, dass durch die Lues ebenso wie duirch den Alkoholismus der Boden für andere Schädigungen vorbereitet und geebnet wird. Und solcher Schidigungen bietet der Marinedienst besonders unter den ungewohnten und fremdartigen Verhältnissen im Ausland nur zu viele.

Ein weiteres ursüchliches Moment für die Auslösung stärkerer seelischer Störungen in der Warine müssen wir in intensiven und wiederholten psychischen Finwirkangen suchen. Vor Allem bei längerem Aufenthalt im Ausland, zumal an Bord der kleineren Schiffe mit ibren unzureichenden Wohn- und Unterkunftsverbältnissen, haben die vielen Reibungsflïchen im dienstlichen wie ausserdienstlichen Verkehr leicht starke Störungen des seelischen Gleichgewichtes zur Folge und können bei weniger widerstandsfähigen Individuen um so leichter zu psychischen Erkrankungen Anlass geben, je mehr die Betroffenen den schädigenden Einwirkungen des Tropenklimas, der Ernährung, kürperlicher Anstrengung und Strapazen, überstandener Krankheiten u. s. w. ausgesetzt gewesen waren. In den Sanitätsberichten der Marine finden wir denn auch verschiedentlich solche Fälle erwähnt, wo heftige Gemüthserregungen stärkere seelische Störungen im Gefolge batten. So trat z. B. transitorische Hanie bei einem an nervösen Herzklopfen leidenden Haschinisten an Bord S. M. S. "Höwe" in Afrika unter dem Einfluss 
dienstlicher Gemüthserregungen auf. Dieselbe kam plötzlich zum Ausbruch mit einem Anfall zorniger Tobsucht, welche sich in einem wilden Bewegungsdrange, thätlichen Angriffen und lauten Verwünschungen in verworrener Ideenflucht offenbarte. Der Anfall ging nach längerem Chloralsehlaf rasch vorüber mit völliger Erinnerungslosigkeit an das Vorgefallene. Es folgte Heimsendung und Invalidisirung. Auch sonst handelte es sich fast stets um acute Manieen, die mit einem heftigen Wuth- und Tobsuchtsanfall im Anschluss an starke Gemüthsbewegungen auszubrechen pflegten.

Ein wichtiger Factor, der bei all den aufgeführten Schädlichkeiten nicht wenig dazu beiträgt, dieselben eine so starke Einwirkung auf die seelische Sphäre der Betroffenen ausüben zu lassen, liegt in dem Gefühl der Hoffnungslosigkeit, der so geringen Aussicht, den unleidlich gewordenen Verhältnissen bald zu entrinnen. Die Commandos dauern meist 2-3 Jahre für das Ausland und endlos erscheint die Zeit und unerträglich Demjenigen, der an einer völligen Wiederherstellung der körperlichen und seelischen Widerstandskraft unter den ungünstigen Umständeln verzweifeln zu müssen glaubt, oder der unter dem Einfluss fortgesetzter Gemüthserregungen in eine missliche Stellung seinen Vorgesetzten gegenüber gerathen ist. Die Aussichtslosigkeit einer baldigen Loslösung aus der verhassten Umgebung nimmt den letzten Rest der Fnergie und macht den Betroffenen zu einem willenlosen Spielball seiner krankhaft gestörten Empfindungen, Gefühle und Launen. Dass dabei ein Gedeiben des Körpers nieht möglich ist, liegt auf der Hand. Störungen des Appetits und der Verdauung bestehen meist schon, solche nervöser Art von Seiten des Herzens treten bald hinzu und es entwickelt sich der nur zu bekannte wechselvolle Zustand des Neurasthenikers, der dem Kranken, seinen Kameraden und seinen Vorgesetzten, nicht zum wenigsten den Aerzten zur Last fällt. Nach längerem Aufenthalt in den Tropen, besonders atuf der ostasiatischen Station erfuhren namentlich in den letzten Jahren die Beschwerden der an Malaria, Ruhr und Typhus Erkrankten eine wesentliche Verschlimmerung durch hinzutretende Neurasthenieen. Es würde zu weit führen, den vielgestaltigen Beziehungen, welche zwischen dem Auftreten von seelischen Erkrankingen und diesen sogenannten grossen Neurosen (Neurasthenie, Hysterie und Epilepse) bestehen, in der Marine genauer nachzuspüren. Die enorme Zunahme der beiden ersteren speciell in den letzten Jahren würde allein schon eine gesonderte Betrachtung der für ihre zunehmende Häufigkeit bei der Marine in Betracht kommenden Verhältnisse rechtfertigen. Für unseren Zweck bleibt die Thatsache wichtig, dass Neurasthenien und Hysterieen in einem nicht geringen. Theil der Fälle mit schwereren 
psychischen Erscheinungen verliefen, aus denen sich späterhin reine Geisteskrankheiten entwickelten. Demgemäss ist auch der wachsende Antheil der wegen neurasthenischer Beschwerden erfolgten Invalidisirungen von grosser Bedeutung, zumal diese Krankheitserscheinungen fast ausnahmslos ältere Unteroffiziere, Deckoffziere und Offiziere befielen, welche für die Entstehung ihrer Leiden die ungünstigen Einflüsse des Borddienstes in Verbindung mit den aussergewöhnlichen klimatischen Einwirkungen im Auslande verantwortlich machten.

Bei den Hysterikern, die häufiger unter den jüngeren Maunschaften anzutreffen waren, wurde in der Mehrzahl der Fälle erbliche Anlage und nervöse Disposition festgestellt. Bei einer nicht unerheblichen Anzahl kam es theils zu leichteren und vorübergehenden Störungen der seelischen Sphäre, theils schlossen sich schwere depressive Zustände mit zeitweiligen Bewusstseinstribungen und Selbstmordgedanken an, die aut hysterisches Irresein schliessen liessen. Als ausiösende Ursachen kamen neben Unfällen mit Kopfverletzungen namentlich die Einwirkungen der Hitze in Betracht. Zuweilen wurden auch und zwar mehr bei älteren Mannschaften, psychische Erregungen, dienstlícher Aerger, verletztes Ehhrgefühl, unglïckliche Familienverhältnisse als Entstehungsursachen angenommen.

Seelische Störungen nach Epilepsie kommen in der Yarine scheinbar etwas häufiger zur Beobachtung als bei der Armee. Die Erscheimungen bestanden neben ausgesprochenem epileptischen Irresein in vorübergehenden Tobsuchtsanfällen und hochgradigen Erregungszuständen. Die durch Hitzeeinwirkungen, sei es Tropenhitze, oder Hitze vor den Feuern in den Heiz-und Haschinenräumen ausgelösten epileptischen Anfälle scheinen eine gewisse verstärkte Neigung za besitzen, sich mit seelischen Stïrungen za combiniren.

Eine dem Marinedienst ganz besonders eigenthümliche Erscheinung, die Seekrankheit, führte nur in ganz vereinzelten Fällen zu seelischen Erkrankungen. In den Sanitätsberichten der letzten 30 Jahre ist nur über einen einzigen derartigen Fall berichtet, und zwar aus den Jahren 1885/87. Es heisst über diesen Fall: „Ein Heizer von einem T'orpedoboot, welchel bei den diesen Fabrzeugen eigenen starken Bewegungen lange Zeit und unausgesetzt an Seekrankheit litt, sprang in einem Anfall von psychischer Depression und in dem dunkelen Gefuihl, dass auf irgend eine Weise diesem grässlichen Zustande ein Ende gemacht werden müsse, bei Skagen ïber Bord. Er wurde gerettet, blieb aber aut dem Aviso "Blifz" seekrank und wurde schliesslich als seedienstuntauglich dem Marinetheil zurücküberwiesen. Derartige Fälle sind in der Jlarine sehr ungewöhnlich und im Allgemeinen erreicht die Seekrank- 
heit nur im ersten Anfang der Seedienstzeit so hohe Grade, dass die Dienstfähigkeit vorübergehend beeinträchtigt wird".

Alle die in dem soeben abgehandelten Kapitel erwähnten Umstände dienen zur Erklärung des grossen Unterschiedes in der Zahl der wegen Geisteskrankheiten und verwandter Leiden erfolgten Dienstentlassungen als Ganzinvalide in der Harine gegenüber der Armee. Es wird hiernach leicht verständlich, dass durch die speciell im weiteren Verlauf des Yarinedienstes zur vollen Wirkung gelangenden schädigenden Einflüsse, wie Neurasthenie, Trunksucht, Lues, Malaria, Ruhr, Hitzschlag, Unfall u. a. die Höhe der Invaliditätsziffer hier bedeutend ungünstiger beeinflusst wird, als bei der Landarmee.

Es ist verschiedentlich versucht worden, die einzelnen Formen der seelischen Erkrankungen, die bei Soldaten des ofteren zur Beobachtung gelangen, genauer zu classificiren und an der Hand einer solchen Eintheilung das besonders häufige Vorkommen der einen oder anderen Geistesstörung nachzuweisen. Eine einheitliche und exacte Eintheilung gehört aber zur Zeit noch za den frommen Wünschen, da über die Grundsätze und Gesichtspunkte, nach denen dieselbe aufzustellen wäre, bei den massgebenden Psychiatern noch die verschiedensten Ansichten herrschen. Auch über die Werthschätzung der Ursachen der Geisteslrankheiten ist noch keine völlige Uebereinstimmung erzielt, wemngleich man in der jüngsten Zeit ziemlich allgemein der Ansicht zuneizt, dass die äusseren störenden Einflüsse zumeist nur als Gelegenbeitsursachen die in der Anlage schon vorhandene Krankheit anslösen. Auf unsere Verhäitnisse übertragen heisst dals, dass die schädigenden Einflüsse des dienstlichen Lebens nur dann eine Gefahr für die Seele bedingen, wenu es sich um ein Gehirn mit krankhaft herabgesetzter Widerstandsfahigkeit handelt. Wenngleich im Allgemeinen bei den Personen des Wehrstandes natürlich alle die seelischen Erkrankungen vorkommen können, die auch sonst beobachtet werden, so erscheint es doch schon in Folge der Einwirkungen des Geschlechtes und des jugendlichen Alters verständlich, dass gewisse Krnnkheitsformen sich durch ihre grössere Hänfigkeit auszeichnen. So herrschen in den ersten Dienstjabren speciell bei den Rekruten die Schwachsinnsformen vor, denen sich die aeuten Depressions- und Exaltationszustände anschliessen. Späterhin treten die Paralysen, die Formen des epileptischen Irreseins, die Paranoia und die Hanie mehr in den Vordergrund.

Genauere Zahlen ïber die Häufigkeit der einzelnen Krankheitsformen bei der preussischen Armee sind nur im Bericht der Jahre 1884/8\% angeführt. Hier finden sich unter $5 \pm \$$ Geisteskranken $52=9, \pm \mathrm{pCt}$. mit angeborenem Schwachsinn, "die überwiegende Mehrzahl der beob- 
achteten Fälle gehört der melancholischen Geistesstörung an"; es sind dies 79 Fälle $=17,7$ pCt. 20 Fälle $=4,5$ pCt. betrafen epileptisches Irresein, ebenso viele Fälle waren Paralysen. Geistesstörungen, welche der Paranoia zuzurechnen sind, wurden verbältnissmåssig selten beobachtet $(2, \bar{\tau} p C t$.$) . In den Berichten der anderen Jalure wird fast stets$ gleichmässig wiederholt, dass unter den eigentlichen Geisteskrankheiten an Zahl die Melancholie in ersten Linie stehe. Eine genauere Zusammenstellung der eivzelnen Geisteskrankheiten zu klinischen Diagnosen liefern die Sanitätsberichte der bayrischen Armee, und zwar bei Mischformen unter besonderer Berücksichtigung nur derjenigen Störung, welche im Vordergrunde des Krankheitsbildes steht. (Eine nicht geringe Anzahl ron im Sinne der H. O. Anl. 4b, 14 hochgradig geistig Beschränkten und daher bald nach der Einstellung Entlassenen ist nicht miteingeschlossen.)

Hiernach litten in der bayerischen Armee an:

\begin{tabular}{|c|c|c|c|c|c|c|c|}
\hline & $\begin{array}{l}\bar{\sigma} \\
\mathscr{D} \\
\infty \\
D\end{array}$ & 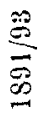 & 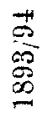 & $\frac{\mathscr{O}}{\stackrel{\mathscr{D}}{\mathscr{D}}}$ & 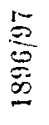 & $\frac{\infty}{\stackrel{\infty}{\sigma}}$ & $\begin{array}{l}\mathscr{D} \\
\stackrel{D}{\infty} \\
\stackrel{\infty}{\infty}\end{array}$ \\
\hline Melancholie & 11 & 23 & 9 & 13 & 7 & 4 & 8 \\
\hline originärer Verrücktheit & 5 & 8 & 3 & 4 & 2 & 2 & 6 \\
\hline paralytischem Irresein . & 5 & 3 & 3 & 2 & 1 & 1 & 3 \\
\hline epileptischem Irresein. & 9 & 9 & 2 & 3 & 3 & ? & 3 \\
\hline acuter Manie . . & 9 & 6 & 6 & 8 & - & 2 & -- \\
\hline alkoholischem Irresein & $\mathrm{I}$ & 2 & 3 & 2 & 2 & - & 3 \\
\hline moralischem Irresein & 1 & 3 & 1 & 4 & - & - & - \\
\hline periodischer Tobsucht. . & 2 & 2 & 2 & 3 & - & - & - \\
\hline hallucinatorischem Verfolgungswahn & 3 & 7 & 3 & 10 & 1 & - & 2 \\
\hline Schwachsinn (Blödsinn). . . & 5 & 6 & 6 & 19 & - & - & 1 \\
\hline Collapsdelirium . . . . & $\div$ & 2 & - & - & - & - & - \\
\hline hysterischem Irresein & - & 1 & - & - & -.. & - & - \\
\hline neurasthenischem Irresein & - & 1 & - & - & - & - & - \\
\hline conträrer Sexualempfindung & - & - & 1 & - & - & - & - \\
\hline Somnambulismus... & - & - & 1 & - & - & - & 2 \\
\hline Hypochondrie ..... & - & - & - & 4 & - & - & - \\
\hline
\end{tabular}

Eine ähnliche Zusammenstellung lässt sich aus den Harine-Sanitätsberichten der letzten 10 Jahre gewinnen, wie sie auf der folgenden Seite wiedergegeben ist. Schon ein Blick auf die grossen Verschiedenheiten sowohl in den jährlichen Zugängen als auch hei einem Vergleich der beiden Uebersichten lässt die wenig einheitliche Einreihung der Krankheitsfälle in dell einzelnen Berichtszeiträumen und bei den rerschiedenen Wehrgattungen rermutben. Eine solche ist schon aus dem Grunde oft unmöglich, weil die Geisteskranken bei den Truppen 
zu kurze Zeit in Behandlung sind, um in jedem Falle eine genaue klinische Diagnosenstellung zu ermöglichen. "Wir müssen uns meist mit der Erkennung einer Zustandsform nach der Gruppirang der hervorstechendsten Symptome begnügen, ohne dieselbe einer bestimmten Krankheitsart zuzuweisen, denn die Aufgabe des Militärarztes ist gelöst, wenn die Dienstuntauglichkeit des Geisteskranken oder seine gesetzliche Unverantwortlichkeit entschieden ist" $\left.{ }^{11}\right)$. Sein weiteres Schicksal entzieht sich dann unserer Beobachtung. Es erscheint daher unzulässig, aus den von verschiedenen Autoren versuchten statistischen Berechnungen der Häufigkeit der einzelnen Seelenstörungen bei der Armee, sowie aus unseren aus den Marine-Sanitätsberichten gewonnenen Zahlen einen auf statistischer Grundlage beruhenden sicheren Rückschluss über die Frequenz dieser Erkrankungsformen zu ziehen.

Es litten in der Marine an:

\begin{tabular}{|c|c|c|c|c|c|c|c|}
\hline & $\frac{\stackrel{\infty}{\stackrel{9}{g}}}{\stackrel{\Phi}{\infty}}$ & 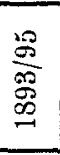 & $\begin{array}{l}\frac{5}{2} \\
\frac{5}{20} \\
\stackrel{\infty}{D}\end{array}$ & $\underset{\stackrel{\mathscr{D}}{\mathscr{S}}}{\stackrel{\mathscr{D}}{\mathscr{D}}}$ & 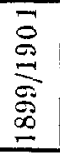 & $\begin{array}{l}\vec{\Xi} \\
\stackrel{\Xi}{\Xi} \\
\stackrel{\Xi}{\Xi}\end{array}$ & 导 \\
\hline $\begin{array}{l}\text { Paranoia (Terrücktheit) } \\
\text { Melancholie }\end{array}$ & $\begin{array}{l}2 \\
7 \\
- \\
- \\
-1 \\
2\end{array}$ & $\begin{array}{r}7 \\
2 \\
6 \\
5 \\
- \\
2 \\
-1 \\
1\end{array}$ & $\begin{array}{r}2 \\
6 \\
4 \\
5 \\
1 \\
1 \\
1 \\
4\end{array}$ & $\begin{array}{r}11 \\
7 \\
2 \\
4 \\
-2 \\
1 \\
-2\end{array}$ & $\begin{array}{c}8 \\
7 \\
3 \\
3 \\
3 \\
3 \\
4 \\
-5\end{array}$ & $\begin{array}{c}39 \\
29 \\
16 \\
17 \\
4)^{2} 21 \\
8 \\
7 \\
1 \\
14\end{array}$ & $\begin{array}{r}21,3 \\
90,6 \\
11,3 \\
14.8 \\
5,6 \\
4,9 \\
0,7 \\
9,9\end{array}$ \\
\hline Summa . & 13 & 24 & 24 & 29 & 36 & 126 & - \\
\hline
\end{tabular}

Nach dieser Tabelle müssten im Gegensatz zur Armee bezüglich der Häufigkeit der einzelnen Geisteskrankheiten in der Marine die paranoischen und melancholischen Zustände an die Spitze treten. Sie würden allein jede etwas mehr als $1 / 5$ aller in den letzten 10 Jahren beobachteten Geisteskrankheiten ausmachen. In einem gewissen $\mathrm{Ab}$ stande folgen erst die Formen des Schwachsinnes, die bei der Armee den Haupttheil aller seelischen Erkrankungen darstellen. Weiterhin kommen die Manien und Paralysen und zum Schluss die Formen des alkoholischen, epileptischen und hysterischen Irreseins.

Wenn es zulässig wäre, einen oberflächlichen Vergleich dieser für die Marine gewonnenen Werthe mit den noch weniger beweiskräftigen oben angeführten Ziffern der 4 jährigen Berichtsperiode $1884 / 88$ bei der

1) Düms, Handbuch der Militärkrankheiten. Bd. III. 
Armee anzustellen, so müsste die Paranoia z. B. bei der Nlarine fast 10 mal so häufig zur Beobachtung gelangen, als bei der Armee, und die Frkrankungen an Paralyse doppelt so bäufig. Gleiche Werthe hätten nur die epileptischen Seelenstörungen aufzuweisen, während die melancholischen Zustände bei der Marine nur wenig zahlreicher vorkämen, als im Heere. Auffallend und genauerer Beachtung werth ist der Umstand, dass bei beiden Wehrgattungen die Melancholie so ausserordentlich häufig unter den seelischen Erkrankungen angetroffen wird, und dass dieselbe in den Sanitätsberichten der Marine noch öfter erwähnt wird, als die statistische Zusammenstellung vermuthen lässt. Darüber sind sich aber alle Autoren einig, dass jedenfalls in der Armee die verschiedenen Schwachsinnsformen einschliesslich der gei stigen Beschränktheit den Haupttheil aller Geistesstörungen ausmachen. Es ist die Annahme nicht von der Hand zu weisen, dass sich unter der Diagnose Melancholie manche Fälle von Depressionszuständen bei jugendlichem Schwachsinn verbergen, bei denen das hervorstechendste Symptom der Depression Schuld an der irreführenden Namengebung trägt. Es muss das häufige Vorkommen der Melancholie um so mehr auftallen, als dieselbe sonst eine zwar in allen Lebensaltern zur Beobachtung kommende Krankheitsform ist, im höheren Lebensalter aber entschieden häufiger anzutreffen ist, als im jugendlichen.

Für die Marine scheint diese Annahme un so mehr Berechtigung $z u$ haben, weil verhältnissmässig recht wenige Fälle von Schwachsinn in den Sanitütsberichten aufgeführt sind, jedenfalls viel weniger als in den Armeeberichten. Zwar lässt sich über die wirkliche Häufigkeit grade dieser Erkrankungen überhaupt nur schwer ein richtiges Urtheil bilden, doch spricht schon der Umstand gegen die Annahme einer relativen Seltenheit bei beiden Wehrgattungen, dass diese Krankheitsformen grade in dem Alter am häufigsten zur Entwicklung kommen, welches in die erste Dienstzeit der wehrfähigen Mannschaften fällt. Auch kann man von dem erworbenen Schwachsinn nicht behaupten, dass er bei den Aushebungen schwer zu überseben sei und daher Einstellungen solcher Minderwerthigen meistens vermieden würden. Im Gegentheil passiren solche Rekruten, ebenso wie die mit angeborenem Schwachsinn bis zur Einstellung meist als geistig normale Menschen und fallen erst im Verlaufe der ersten Nonate ihrer Dienstzeit durch ihr eigenthümliches geistiges Verhalten auf, nachdem sie verschiedentlich für dienstliche Versehen und Entfernungen ron der Truppe bestraft werden mussten. Im Vordergrund der ersten Krankheitserscheinungen stehen fast stets, besonders in den schwereren Fällen, ausgesprochene depressive Zustände, die häufig mit Heimwehgedanken einhergehen. Doch auch in den 
leichteren Fällen wird die Aufmerksamkeit auf das etwaige Bestehen einer geistigen Erkrankung erst dann gelenkt, wenn nach vorhergegangenen Dienstvernachlässigungen, Strafen u. s. w. auffallende Depressionszustände unter stärkerer Betheiligung des Gefühlslebens sich geltend machen. Diese hervorstechenden Symptome hochgradiger trauriger Verstimmung werden als Melancholie gedeutet und füluren als solche zur Entlassung des Kranken, ohne dass die weitere Entwickelung des Zustandes, welche allein erst die richtige Erkennung zugelassen hätte, abgewartet werden konnte. Auf diese Weise muss einerseits das auffallend häufige Vorkommen der Melancholie, andererseits die in sich widerspruchsvolle Seltenheit des erworbenen Schwachsinns in der Marinestatistik ihre Erklärung finden.

Es darf aber nicht unberïcksichtigt bleiben, dass auch bei anderen Frkrankungen, z. B. bei den schweren neurasthenischen und hysterischen Zuständen die melaucholischen Verstimmungen so stark das Krankbeitsbild beherrschen können, dass man ans ihnen die Benennung hergeleitet hat.

Die Helancholie als reine Krankheitsform ist jedenfalls in Armee und Marine nicht bäufiger als bei der Civilbevölkerung, bei der sie erst im Rückbildungsalter aufzutreten pflegt. Wobl aber treten bei manchen der bei der Wehrmacht zur Beobachtung kommenden seelischen Erkrankungen melancholische Symptome am auffallendsten und am triuhzeitigsten in die Erscheinung. Die Entlassung soleher Kranken geht aber vor sich, sobald die Dienstunfähigkeit erkannt ist, nicht erst dann, wenn die klinische Diagnose durch längere Beobachtung und Behandlung unzweifelhaft festgestellt ist. Dass aber und warum melancholische $\mathrm{Zu}$ stände im Beginn und Verlauf seelischer Erkrankungen grade bei der Marine so besonders häufig im Vordergrund der krankhaften Störungen stehen und das Krankheitsbild beherrschen, findet seine Erklärung darin, dass starke Depressionszustände im Anschluss an schwere Infectionskrankheiten nach Verunglückungen u. s. w. im Auslande unter den ungünstigen und ungewohnten Verhältnissen des Klimas, der Hitze, der Enährung, der Unterkunft und der Umgebung leichter zum Ausbruch zu kommen pflegen als in den bekannten und geordneten Verhältnissen der Heimath. Der Kranke empfindet naturgemäss das Fernbleiben von der Heimath, von theilnehmender sympathischer Umgebung und erleichterndem Trost und Beistand viel schwerer und intensiver als in gesunden Tagen. Der Wunsch, diesen ungünstigen Verhältnissen so schnell wie möglich zu entrinnen, die ihn keine baldige Genesung erhoffen lassen, und die sich steigernde Sehnsucht nach der Heimath, wo er allein Heilung und Wiederherstellung erwarten zu können glaubt, die 
augenblickliche psychische Unmöglichkeit, all diesen Einwirkungen ein wirksames seelisches Gegengewicht zu bieten, lassen die Erscheinungen der traurigen Verstimmtheit und schmerzlichen Gemïthsdepression derart vorherrschen, dass eine reine Melancholie vorgetäuscht werden kann. Glücklicherweise gelangen eine Reibe der hierher gehörigen Fälle nach Rückkehr in die Heimath zum Ausgleich, nicht selten hat aber die seelische Störung so tiefe Wurzel gefasst, dass durch sie die Dienstfähigkeit in Frage gestellt wird, längst nachdem das Grundleiden gehoben ist.

Schliesslich spricht noch die für die Marine nachgewiesene gerin= gere Selbstmordneigung gegen die Annahme, dass reine Melancholieen, die bekanntermassen mit Vorliebe zu Angriffen auf das eigene Leben führen, in der Marine eine so grosse Frequenz haben, als es nach der Statistik der Fall zu sein scheint.

Unter den verschiedenen Formen des Schwachsinnes, die den Löwenantheil der seelischen Erkrankungen bei der Armee sicher, bei der Harine wahrscheinlich darstellen, nimmt der angeborene Scbwachsinn den breitesten Raum ein. Er betrifft den grössten Theil derjenigen Maunschaften, die sehr bald nach ihrer Einstellung wieder entlassen werden müssen. Diese Erkrankungsform umfasst alle jene Zustände, die Koch mit einem treffenden Ausdruck als npsychopathische Minderwerthigkeiten" bezeichnet hat. Ihre grosse Häufigkeit bei der Webrmacht findet ihre Erklärung darin, dass unter diesen Begriff im militärischen Sinne auch die leichtesten Grade von Schwachsinn und geistiger Beschränktheit fallen, die den damit Behafteten als nicht mehr tauglich für den Dienst kennzeichnen. $D a$ sie in den Statistiken den reinen Geisteskrankheiten zugerechnet sind, muss die relative Durchschnittshöhe dieser Erkrankungen beim Militär gegenüber der geringeren Höhe in der Civilbevölkerung zum grossen Theil auf ihr Conto gesetzt werden. Solche Schwachsinnige waren in ihrer bisherigen Umgebung vielfach durchaus nicht als geistig minderwerthig aufgefallen und vermochten den an sie gestellten Ansprüchen zu genügen, ebenso wie sie nach ihrer Entlassung scheinbar als geistig Gesunde in den Kreis ihrer früheren Thätigkeit und Umgebung zurückkehren. Es braucht eben nicht nothwendiger Weise jede psychopathische Minderwerthigkeit in eine Psychose überzugehen. Thatsächlich geht sie aber in eine solche über, wenn auslösende Gelegenheitsursachen dazu kommen, die darum wirksam werden konnten, weil die Betreffenden schon vorher psychopathisch geschädigt waren. Solche Lrsachen bietet aber das Militär- und Marineleben in grossem Maasse. Daher gesehieht es nur zu recht, solche Individuen als unbrauchbar aus dem Dienste zu entlassen, in der 
Erwägung, dass „der straffe Rahmen des llilitärlebens, da er für die Eigenthümlichkeiten und Schwächen des Einzelnen keinen Raum bietet, für alle Diejenigen, die mit ihrem geistigen Erbtheil zu kurz gekommen sind und Schwierigkeiten haben, sich den Verhältnissen anzupassen, gefährlich werden kann" (Düms).

Nahe verwandt den Zuständen des angeborenen Schwachsinnes sind die Formen des Schwachsinnes, bei denen die Störungen hauptsächlich im Bereich des Gemüthes liegen, und die man deshalb mit dem Namen "moralischer Schwachsinn" bezeichnet hat. Man versteht darunter angeborene oder in der ersten Entwicklung erworbene, in der Constitution begründete Defectzustände, deren wesentlicher Zug der Mangel oder die Verkehrung der sittlichen Gefühle und Strebungen ist. Die genaue Kenntniss dieser Erkrankung ist für uns von grösster Wichtigkeit, weil wie bei den anderen Schwachsinnsformen die ersten Aeusserungen des Leidens in dem Lebensalter auftreten, welches mit dem Diensteintritt zusammenfällt. Daher werden solche Individuell bei der ersten Untersuchung ebenfalls vielfach für geistig gesund gebalten. Der Dienst stellt aber so ungewohnte Anforderungen an das psychische und auch ethische Leistungsvermögen, dass das prädisponirte Gehirn diesen Ansprüchen gegenüber versagt. Wird der Zustand nicht frühzeitig genug anerkannt, so macht der Schwachsinnige sich strafbarer Handlungen schuldig, fül die ihm die Verantwortlichkeit nicht aufgebürdet werden kann. Deshalb sind solche Individuen durchaus ungeeignet zur Fortsetzung des Dienstes und sofort nach Erkennung des Leidens zu entlassen. Denn sie werden stets wieder in Conflict mit den eisernen Forderungen der Disciplin gerathen, der sie sich nicht fügen können und dann bilden sie auch eine grosse Gefahr für ihre Kameraden, auf die ihr schlechtes Beispiel ansteckend wirken kann. Für die Kategorie solcher Kranken das Militärleben als eine gesunde und gute Schnle anzusehen, ist durchaus falsch, wenngleich nicht verkannt werden soll, dass das regelmässige und geregelte Leben des Dienstes in manchen Fiallen einen heilsamen Einfluss auf solche Kranke ausüben kann. Doch ist das nicht der Zweck der militärischen Ausbildung, zu der nur körperlich und geistig ganz Gesunde herangezogen werden dürfen.

Neben den Formen des Schwachsinues und den melancholischen Zuständen, welche zusammen mehr als ein Drittel aller seelischen Erkrankungen und der Marine darstellen, sind die primäre Verrücktheit und die progressiven Paralysen recht häufig vorkommende Geisteskrankheiten. Im Gegensatz zu den erstgenannten, welche vorzugsweise unter den Rekruten und jüngeren Dienstklassen vorherrschen, 
betreffen die letzteren fast nur ältere, dem Unteroffiziers- und Offiziers. stande Angehörige.

Zur Erklärung des bereits erwähnten auffallenden Missrerhältnisses zwischen der Häufigkeit der Paranoia bei Armee und Marine zu Ungunsten der letzteren muss noch mebr wie bei Schwachsinn und Melancholie die zur Zeit herrschende Unsicherheit der Begriffsbestimmung dieser Erkrankung und ihrer Begrenzung herangezogen werden. Bei keiner anderen Krankheitsart gehen die Ansichten über ihre Zugehörigkeit so weit auseinander, wie bei der Paranoia. Schon die grosse Verschiedenheit in den einzelnen Jahren bei der Marine lässt darauf schliessen, dass die Einreihung der Krankheitsfälle in diese Bezeichnung keine einheitliche gewesen ist. Auch das verhältnissmässig zu jugendliche Alter spricht gegen die Annahme, dass es sich wirklich so oft um diese $\mathrm{Er}$ krankung handelt, die doch in der Regel erst im reiferen Alter von 35 Jahren an anfzutreten pflegt. Wieder sind es wie bei der Melancholie die Formen des Schwachsinnes, besonders die Dementia praecox, welche sieh in nicht geringer Anzahl unter der Diagnose Paranoia verbergen. Lin anderer Theil dürfte unter die epileptischen und hysterischen Seelenstörmngen einzureilhen sein. Wenn nun auch über die absolute Hänfigkeit dieser Krankheit ein einigermassen sicheres Urtheil nicht gewonnen werden kann, so erseheint es doch als sehr wahrscheinlich, dass die Marine mit einem etwas grösseren Antheil vertreten ist, als die Armee.

In ein noch späteres Alter als Paranoia fällt die progressive Paralyse. Sie gelangt deshalb in Armee wie Marine fast ausschliesslich bei alten Unteroffizieren, Deckoffizieren und nicht zum wenigsten bei Offizieren zur Beobachtung. Obwohl es sich bei der Paralyse im Allgemeinen um eine wohl charakterisirte und daher leichter zu bestimmende Erkrankung handelt, können ihre ersten Erscheinungen doch oft so unbestimmter Art sein, dass sie zu dem wechselvollen Bild der Neurasthenie zu passen scheinen, und sicher kommt mancher Paralytiker wegen schwerer Neurasthenie zur Entlassung, ehe die Paralyse als solche offenkundig wurde. Sind schon die Verbältnisse des militärischen Lebens am Lande nicht ungeeignet, zumal im Verein mit den bekannten Schädlichkeiten der Lues und des Alkoholismus vereint den Boden für die Entwickelung der organischen Gehirnveränderungen bei der Paralyse vorzubereiten, so muss dies für die specifischen Eigenthümlichkeiten des Marinedienstes erst recht betont werden. Ausser den Einflüssen des Alkobols und der Syphilis, die bei der Marine, wenn auch nicht viel bäufiger, so doch intensiver den davon Befallenen be- 
treffen, sind es die grösseren Anstrengungen und noch mehr die psychischen Reizwirkungen, welche im Auslande unter bedeutend ungünstigeren ausseren Verhältnissen zu Stande kommen als in der Heimath. Die schon so oft erwähnten Einwirkungen des wechselnden Klimas, der Temperatur, langwieriger und schwerer Krankheiten, die seelischen Einflüsse des Dienstes mit seiner Verantwortlichkeit und den vielen Reibungstlächen, der Mangel an Erholung, Zerstreuung und Abwechselung, alle diese sind Momente, welche die allgemeine Widerstandsfähigkeit durch ihre schädigende und schwächende Rückwirkung auf das Nervensystem herabsetzen und den Boden für eine beginnende Paralyse in einer viel günstigeren Weise vorbereiten, als unter den gewöhnlichen Verhältnissen am Lande. Es erscheint daher erklärlich, dass die Paralyse in der Marine häufigere Opfer fordert als in der Armee, um so mehr, wie bereits erwähnt, die. zahlreichen im Auslande erworbenen syphilitischen Infectionen sich durch einen schwereren und schnelleren Verlanf auszeichnen und dadurch die Disposition für paralytische Erkrankangen steigern. Ferner liefern die zahlreichen höheren Unteroffiziers- und Deckoffiziersstellen eine geeignete Altersklasse für den häufigen Ausbruch der Paralyse bei der Narine. Auch erscheinen hier die an Bord erkrankten Offiziere in den statistischen Berichten, während dieselben in der Armee nicht mitgerechnet sind.

Reine Manie gelangt in der Marine wohl eben so. selten zur Beobachtung wie in der Armee. Bei den vielen so benannten Krankheitsbildern handelt es sich meist nur um transitorische Bewusstseinsstörumgen, die ihre bauptsächlichste Aeusserung in maniakalischen Anfällen finden. Linter den sie auslösenden Ursachen spielen Alkohol, psychische Affecte, Verletzongen eine hervorragende Rolle, zumal wenn sie ein durch epileptische, hysterische oder neurasthenische Veranlagung geschwächtes Gehirn betreffen. Unter dem Einfluss der Hitze, sowohl in überhitzten Schiffsräumen als auch unter der Tropenhitze, im Anschlnss an starke Gemüthsbewegungen treten bei der Marine recht häufig vorübergehende maniakalische, tobsuchtsähnliche Anfälle auf, welche mit reiner Nanie nichts gemein haben. Weitaus am meisten werden Mannschaften jüngerer Jahrgänge von diesen Erkrankungen betrofien, welche meist mit völliger Heilung enden.

Eng an diese vorübergebenden Psychosen schliessen sich die in Folge acuter oder chronischer Alkoholvergiftungen entstandenen Bewusstseinsstörungen an, von denen bereits oben die Rede war. Bei der pathologiseben Alkoholreaction muss ein deutliches Missverhältniss zwischen der genossenen Alkoholmenge und den durch sie veranlassten Erregungszuständen nachzuweisen sein. Bei der Marine 
werden Alkoholpsychosen im Inlande sicher nicht häufiger beobachtet als bei der Armee. Im Auslande jedoch führen Alkobolvergiftungen, zumal chronische zu zahlreicheren Seelenstörungen in Folge der besonderen Eigenthümlichkeiten des Bordlebens und der klimatischen Einflüsse, welche die allgemeine Widerstandskraft des Körpers berabsetzen und das dadurch in seiner Rüstigkeit geschwächte Gehirn für die verheerenden Wirkungen des Alkohols empfänglicher machen. Sie dienen zur Erklärung der höhen Durchschnittsziffern dieser Erkrankungen in der Marine. Auch nach einmaligem übermässig starkem Alkoholgenuss bei grosser Hitze oder nach vorhergegangenen besonderen körperlichen Anstrengungen aufgetretene acute Seelenstörungen finden in den Marine-Sanitätsberichten nicht selten Erwähnung.

Dem alkoholischen Irresein steht nach der statistischen Aufstellung in Bezug auf seine Häufigkeit in der Vlarine das epileptische Irresein kaum nach; beide machen ungefähr je 5 pCt. aller seelischen Erkrankungen aus. Wenn diese Zahl bei den alkoholischen Seelenstörungen im Grossen und Ganzen der Wahrheit entsprechen dürfte, so ist dieselbe bezüglich der auf epileptischer Grundlage entstandenen entschieden zu niedrig gegriffen. Hieran trägt wie bei so manchen anderen geistigen Erkrankungen wiederum die Unsicherheit der Einreihung und Abgrenzung der Krankheitsbilder die Schuld. Denn es sind nicht die tiefen Intelligenzdefecte, welche sich bei langandauernder Epilepsie auszubilden pflegen, die gewöhnlich unserer Beurtheilung unterworfen werden, sondern die vorübergehenden acuten seelischen Störungen, deren Erkennung als epileptische Aequivalente oder postepileptische transitorische Geistesstörungen nicht selten auf Schwierigkeiten stösst. Schwachsiml, Trunksucht, Manie, hallucinatorische Verwirrtheit, unter diesen und anderen Diagnosen verbergen sich manche psychische Affectionen, welche dem Boden einer epileptischen Veranlagung entstammen und deren Erkrankung als solche erst durch eine länger dauernde oder wiederbolte Beobachtung ermöglicht wird. Obwohl Erkrankungen an Epilepsie in der Narine im Verlauf der letzten 12 Jabre seit 1890 nur unbedeutend (ungefähr um 1/6) häufiger waren als in der Armee, scheinen dieselben doch unter den Einwirkungen des Marinedienstes relativ zahlreichere seelische Störungen im Gefolge zu haben. Gelegenheitsursachen zum Ausbruch solcher Erkrankungen bietet der Marinedienst sicher in viel ausgiebigerem Maasse als der Dienst bei der Laudtruppe. Nicht allein im Auslande, wo unter deu bekannten die allgemeine Widerstandskraft schädigenden Einwirkungen der häufigere Ausbruch des epileptischen Irreseins leicht erklärlich ist, sondern auch im Inlande wird die Auslösung mancher auf epileptischer Grundlage beruhender Seelen- 
störungen den Besonderheiten des Marinedienstes zur Last gelegt werden miissen. Diese bestehen hier wiederum in erster Linie in den ungünstigen Einflüssen der Hitze in den Heiz- und Maschinenräumen der modernen Kriegsschiffe, sodann in den an Bord nicht seltenen Unglücksfällen und Verletzungen. Besonders häufig bei Hitzeeinwirkungen, dann aber auch nach Verletzungen zumal des Kopfes werden epileptische Anfälle mit auffallender Betheiligung der seelischen Sphäre bei bis dabin scheinbar völlig gesunden Individuen hervorgerufen, die in wenigen Tagen oder Wochen verschwinden, ohne je wieder beobachtet zu werden. Die herabgesetzte Widerstandsfähigkeit des epileptisch Veranlagten fand in Folge der besonders stark einwirkenden Schädlichkeiten ihren Ausdruck im Ausbruch eines Krampfanfalls mit Tobsuchts- und Verwirrungszuständen, die den eigentlichen Anfall noch geraume Zeit überdauern können. Ein neuer Anfall bleibt vielfach aus, weil die Widerstandskraft des Gehirns sich unterdess wieder gehoben hat und ähnlichen Insulten nicht wieder ausgesetzt war. Zuweilen bleibt die Erkennung des Leidens dunkel und der Mann wird dem Dienste erbalten, ohne je wieder zu erkranken. Namentlich von den Schiffen im Anslande wird über derartige Fälle nicht selten berichtet.

Eine Form des epileptischen Aequivalentes, die in der letzten Zeit bei der Armee Gegenstand besonderer Würdigung geworden ist und der wir auch in der Marine nicht selten begegnen, wird mit dem Namen "kr an k h a fter Wandertrieb" bezeichnet. Besser würde man sie noch „epilepti. scher Wandertrieb" nennen. Es handelt sich nämlich um transitorische Anfälle von psychischer Störung auf epileptischer Grundlage, theilweise mit Erhaltung des Bewusstseins, die ihren Ausdruck darin finden, dass die Krankeu obne jeden ausreichenden Grund, meist auch unter unverständlichen und räthselhaften Umständen sich aus dem Dienste entfernen. In der grössten Mehrzahl sind es erblich belastete Kenschen, bei denen sich von Jugend auf das Fortlaufen als eine eigenthümlich, periodisch wiederkehrende, durch keine nachweisbaren äusseren Einflüsse bedingte und durch keine Strafe und andere Nachtheile zu beseitigende oder auch nur einzuschränkende Erscheinung eingestellt hat. Durch die straffe Diseiplin und die Einengung in die militärischen Verhältnisse kann dieser krankhafte Trieb für eine geraume Zeit bekämpft werden, doch wird sich stets der mächtige $Z$ wang dieser unheilvollen Neigung gelegentlich einmal wieder geltend machen. Die grade bei der Marine nicht seltenen Desertionen im Auslande sind vielfach, wenn keine anderen Gründe vorliegen, als solche Zustände krankhaften Wandertriebes auf epileptischer Basis aufzufassen, zumal wenn sie, wie es häufig der Fall ist, mit angeborenem oder erworbenem Schwachsinn combinirt sind. 
Hysterisches Irresein, welches bereits kurz besprochen wurde, scheint in der Marine nicht häufiger beobachtet zu werden, als im Heere.

Es erübrigt noch, mit wenigen Worten das Vorkommen der Simu. lation von Geisteskrankheiten zu streifen. Köster weist an der Hand eines grösseren aus der Armee gesammelten Materials die ausserordentliche Seltenheit der Vortäuschung von Geisteskrankheiten nach. Von 11 in drei Jahren beobachteten Fällen stellten sich vier nachträglich als wirkliche Psychosen heraus. Die häufigste Art der simulirten Geistesstörung war Tobsucht mit Eriunerungslosigkeit für die Strafthat, erinnerte also ạn epileptische Dämmerzustände. Sie bilden ebenso oft die Quelle diagnostischer Schwierigkeiten wie die Uebergangsformen des Schwachsinns. In den Berichten der Marine finden wir keinen einzigen Fall von versuchter Vortäuschung einer Geisteskrankheit erwähnt:

$\mathrm{Zu}$ welchen Schlussfolgerungen berechtigen uns nun die Resultate der vergleichenden Statistik bezüglich der Beantwortung der Frage, ob dem Marinedienst ein besonderer Einfluss auf die Entstebung seelischer Erkrankungen zuzuschreiben ist? Der geringe Unterschied in der Häufigkeit der reinen Geisteskrankheiten bei der Marine und der Armee würde an und für sich kaum die Annahme rechtfertigen, dem Mariıedienst SchuJd an dieser grösseren Häufigkeit zu geben. Aus der sehr geringen Höhe der wegen Geisteskrankheiten als dienstunbrauchbar bei der Narine Entlassenen kann aber der Schluss gezogen werden, dass der Uebergang aus dem Civilleben zum Mlarinedienst sowie die erste Zeit desselben nicht in dem Maasse wie beim Heere eine geistige Erkrankungen auslösende Ursache abgiebt. Dahingegen lissst die höhore Zahl der bei der Marine wegen Geisteskrankheiten Invalidisirten anf die Annahme ungïnstiger Einwirkungen des Marinedienstes schliessen, die sich erst im längeren Verlauf desselben geltend machen. Der enorm hohen und wachsenden Zabl der in der Harine an Neurasthenie und Hysterie Erkrankten müssen auch zahlreichere auf der Basis solcher Erkrankungen entstandene seelische Störungen entsprechen. Dass diese den Einwirkungen des Marinedienstes zur Last zu legen sind, ergiebt sich neben dem Unterschiede gegenüber den Zahlen der Armee aus der Thatsache, dass von solchen Erkrankungen in der grössten Mebrzahl ältere Unteroffiziere, Deckoffiziere und Offiziere, also Personen mit längerer Dienstzeit befallen werden. Da aber andererseits diese Leiden in der Marine kaum häufiger zur Invalidität führen als bei der Armee, so ist anzunehmen, dass ein grosser Theil dieser Erkrankungen und damit auch ein entsprechender Theil der auf diesen Zuständen basirenden Störungen der Seele in Heilung übergegangen ist, ohne die Dienstfahhigkeit in Frage zu stellen. 
Die geringere Selbstmordneigung in der Marine gegenüber der Armee berechtigt zu der Annahme, dass die zu Selbstmord Anlass gebenden seelischen Erkrankungen überhaupt seltener in der Marine vorkommen. Da aber die überwiegende ZahI der Selbstmorde in die erste Dienstzeit fällt, so müssen grade die sonst in der frühesten Dienstzeit am häufigsten vorkommenden Geistesstörungen in der Marine seltener sein. Demnach giebt die frühe Dienstzeit in der Marine weniger häufig Gelegenheit zum Ausbruch solcher Erkrankungen als beim Heere. Dass aber bei den Selbstmorden von Unteroffizieren etc. die Marine ein grösseres Contingent stellt, lässt wiederum auf zahlreichere Seeleustörungen im späteren Verlauf des Marinedienstes schliessen.

Wir sehen also, dass dem Marinedienst auf die Auslösung und Entstehung seelischer Erkrankungen bei den jüngeren Mannschaften and in der frühesten Dienstzeit ein besonders ungünstiger Einfluss nicht zuzuschreiben ist. Der Uebergang aus dem Civilleben gestaltet sich ziemlich leicht und giebt deshalb seltener Anlass zum Ausbruch bis dahin verborgen gebliebener Psychosen. Aehnlich verhält es sich in den ersten Uonaten und auch noch Jahren; späterhin ändert sich aber das Verhältniss und das mit den Jahren zunehmende Vorkommen seelischer Erkrankungen, deren Opfer vornehmlich ältere Linteroffiziere etc. sind, lässt auf einen inneren Zusammenhang mit gewissen Eigenthümlichkeiten des Marinedienstes schliessen. Aber auch für den Marinedienst gilt der Satz, dass das Militärfeben wohl eine wesentliche Gefahr für den Ausbruch von Geisteskrankheiten birgt, doch nicht die wirkliche Ursache dieser Störungen ist. Solche Gefahren bietet der Marinedienst in seinem späteren Verlauf nach längerem Aufenthalt an Bord und in ausländischen Gewässern in besonders starkem Maasse. Sie beruhen hier in erster Linie auf den ungünstigen und ungewohnten Verhältnissen des Klimas, der Körperpflege, der engen Unterkunft, der eintönigen Ernährung, sowie der mangelnden Abwechselung und Erholung. Diese ungünstigen äusseren Verbätnisse veranlassen in der Regel nie für sich allein, sondern nur dann den Ausbruch einer seelisehen Erkrankung, wenn sie sich mit gewissen in Folge der Eigenthümlichkeiten des Borddienstes und des längeren Aufentbaltes in ausländischen Gegenden hänfiger und intensiver einwirkenden Momenten combiniren. Hierher gehören vornehmlich die Einflüsse der Hitze, sowohl in Gestalt der Tropenhitze als auch der in den Heiz- und Haschinenräumen erzeugten, die oft zu Hitzschlag mit sich anschliessenden Psychosen führt. Sodann kommen Unglückśfälle, besonders solche mit Betheiligung des Kopfes, die bei den Arbeiten und Manövern an Bord nicht selten sind, als auslösende Uomente seelischer Erkrankungen in Betracht; ferner langan- 
dauernde Einwirkungen grosser körperlicher und geistiger Anstrengungen. Von besonders grosser Bedeutung sind gewisse in den tropischen Gegenden en- und epidemisch auftretende Infectionskrankheiten, wie Malaria, Ruhr, Syphilis u. a. Weiterhin führen Alkoholvergiftungen unter den Einflüssen des Tropenklimas und der Bordverhältnisse zu häufigen Geistes. störungen. Als weiterer wichtiger Factor kommen heftige und andauernde Gemüthserregungen und seelische Einwirkungen in Folge dienstlicher oder privater Unannehmlichkeiten, sowie die Aussichtslosigkeit auf baldige Aenderung als auslösende Ursache in Betracht. Alle diese Momente führen aber in der Mehrzahl der Fälle als indirecte Ursachen seelische Erkrankungen nur da herbei, wo sie auf dem Boden einer ererbten Disposition, auf der Grundlage einer epileptischen, neurasthenischen oder hysterischen Veranlagung zur Entstehung gelangen. Die hauptsächlich bei der Marine vorkommenden Erkrankungen dieser Art genauer zu classificiren, unter bestimmte Krankheitsbilder einzureihen und bezüglich ihrer relativen Häufigkeit abzuschätzen, ist bei der herrschenden Unsicherheit der Begriffsbestimmung und der vielfach zu kurzen Zeit der Beobachtung sehr schwierig und zweifelhaft. Deshalb ist den diesbezüglichen Ergebnissen der statistischen Zusammenstellungen nur ein sehr beschränkter Werth beizumessen. Unter Vergleich mit den bei der Armee herrschenden Verhälnissen sind jedoch gewisse charakteristische Unterschiede in der Häufigkeit des Vorkommens einzelner Geistesstörungen nicht zu verkennen. In den ersten Dienstjabren, speciell bei den Rekruten herrschen bei beiden Wehrgattungen zwar die verschiedenen Schwachsinnsformen vor, denen sich die acuten Depressions- und Exaltationszustände anschliessen, doch gelangen die ersteren bei der Marine bedeutend seltener, und die letzteren meist erst viel später zum Ausbruch als bei der Armee. Für die Anslösung der ersteren bietet demnach der Armeedienst eine viel grössere Gefahr als der Narinedienst und für die letzteren ist dem Marinedieust nicht nur kein besonders ungünstiger Einfluss, sondern eher eine verzögernde Wirkung zuzuschreiben.

In der späteren Dienstzeit treten bei der Armee die Paralysen, die Formen des epileptischen Irreseins, die Paranoia und die Manie mebr in den Vordergrund, weisen aber durchschnittlich eine geringere Häufigkeit auf als bei der Marine, wo vor Allem die Paranoia, die Paralyse und das alkoholische Irresein stark vertreten sind. Die in den Statistiken hüben wie drüben durch ihre Häufigkeit auffallenden melancholischen Zustände sind grossentheils dem Schwachsinn, sowie den in der Marine besonders zahlreich vertretenen neurasthenischen und auch den hysterischen Zuständen zuzuweisen. Auch die hohe Frequenz der Paranoia 
bei der Marine ist hauptsächlich auf Rechnung des Schwachsinns, sowie epileptischer Seelenstörungen zu setzen. Das vermehrte Auftreten der erwähnten Erkrankungen bei der Marine ist den specifischen Einwirkungen des Marinedienstes in seinem späteren Verlauf, wie wir sie oben zusammengefasst haben, mit Recht zuzuschreiben. In hervorragendem Maasse gilt dies auch für die auf neurasthenischer Basis entstandenen Erkrankungen, deren zunehmende Häufigkeit besonders in den letzten Jahren beobachtet wurde. Da alle diese in der Marine zahlreicher auftretenden Geistesstörungen eine länger dauernde Einwirkung der im Verlaufe des Marinedienstes zur Geltung kommenden schädigenden Einflüsse vorausetzen, so ist es erklärlich, dass von diesen Erkrankungen im Allgemeinen nicht die Mannschaften, sondern vielmehr die älteren Jahrgänge der Unteroffiziere, Deckoffiziere und die Offiziere betroffen werden. Aber auch bei diesen verursacht der Marinedienst als solcher allein und für sich nicht derartige Erkrankungen, sondern er ist nur insofern als auslösendes Moment aufzufassen, als die im längeren Verlaufe des Marinedienstes an Bord und in den tropischen Gegenden des Auslandes zur häufigeren und intensiveren Einwirkung gelangenden schädigenden Momente an die körperliche und seelische Widerstandsfähigkeit des Einzelnen erhöhte Anforderungen stellen, die bei weniger resistenten Individuen allerdings bäufiger, zumal auf dem Boden einer neuropathischen Veranlagung die indirecte Veranlassung zur Entstehung und zum Ausbruch seelischer Erkrankungen bilden. 